\title{
Optimum satellite remote sensing of the marine carbonate system using empirical algorithms in the global ocean, the Greater Caribbean, the Amazon Plume and the Bay of Bengal
}

\author{
Peter E. Land ${ }^{\mathrm{a}, *}$, Helen S. Findlay ${ }^{\mathrm{a}}$, Jamie D. Shutler ${ }^{\mathrm{b}}$, Ian G.C. Ashton ${ }^{\mathrm{b}}$, Thomas Holding ${ }^{\mathrm{b}}$, \\ Antoine Grouazel $^{c}$, Fanny Girard-Ardhuin ${ }^{c}$, Nicolas Reul ${ }^{c}$, Jean-Francois Piolle ${ }^{c}$, \\ Bertrand Chapron $^{c}$, Yves Quilfen ${ }^{c}$, Richard G.J. Bellerby ${ }^{\mathrm{d}, \mathrm{e}}$, Punyasloke Bhadury, \\ Joseph Salisbury ${ }^{g}$, Douglas Vandemark ${ }^{g}$, Roberto Sabia ${ }^{h}$ \\ ${ }^{a}$ Plymouth Marine Laboratory, Prospect Place, West Hoe, Plymouth, PL1 3DH, UK \\ ${ }^{\mathrm{b}}$ University of Exeter, Penryn, Cornwall, TR10 9FE, UK \\ ${ }^{\mathrm{c}}$ Ifremer, University Brest, CNRS, IRD, Laboratoire d'Océanographie Physique et Spatiale (LOPS), IUEM, F-29280, Brest, France \\ d SKLEC-NIVA Centre for Marine and Coastal Research, State Key Laboratory for Estuarine and Coastal Research, East China Normal University Zhongshan N. Road, \\ 3663, Shanghai, 200062, China \\ e Norwegian Institute for Water Research, Thormølensgate 53D, N-5006, Bergen, Norway \\ ${ }_{\mathrm{f}}^{\mathrm{f}}$ Department of Biological Sciences, Indian Institute of Science Education and Research Kolkata, Mohanpur, 741 246, West Bengal, India \\ ${ }^{g}$ Ocean Processes Analysis Laboratory, University of New Hampshire, Durham, NH, 3824, United States \\ ${ }^{\mathrm{h}}$ Telespazio-Vega U.K. for European Space Agency (ESA), ESRIN, Frascati, Italy
}

\section{A R T I C L E I N F O}

\section{Keywords:}

Carbonate chemistry

Earth observation

Ocean acidification

Total alkalinity

Dissolved inorganic carbon

SMOS

Aquarius

CORA

HadGEM2-ES

\begin{abstract}
A B S T R A C T
Improving our ability to monitor ocean carbonate chemistry has become a priority as the ocean continues to absorb carbon dioxide from the atmosphere. This long-term uptake is reducing the ocean $\mathrm{pH}$; a process commonly known as ocean acidification. The use of satellite Earth Observation has not yet been thoroughly explored as an option for routinely observing surface ocean carbonate chemistry, although its potential has been highlighted. We demonstrate the suitability of using empirical algorithms to calculate total alkalinity $\left(\mathrm{A}_{\mathrm{T}}\right)$ and total dissolved inorganic carbon $\left(\mathrm{C}_{\mathrm{T}}\right)$, assessing the relative performance of satellite, interpolated in situ, and climatology datasets in reproducing the wider spatial patterns of these two variables. Both $\mathrm{A}_{\mathrm{T}}$ and $\mathrm{C}_{\mathrm{T}}$ in situ data are reproducible, both regionally and globally, using salinity and temperature datasets, with satellite observed salinity from Aquarius and SMOS providing performance comparable to other datasets for the majority of case studies. Global root mean squared difference (RMSD) between in situ validation data and satellite estimates is $17 \mu \mathrm{mol} \mathrm{kg}{ }^{-1}$ with bias $<5 \mu \mathrm{mol} \mathrm{kg}{ }^{-1}$ for $\mathrm{A}_{\mathrm{T}}$ and $30 \mu \mathrm{mol} \mathrm{kg}^{-1}$ with bias $<10 \mu \mathrm{mol} \mathrm{kg}^{-1}$ for $\mathrm{C}_{\mathrm{T}}$. This analysis demonstrates that satellite sensors provide a credible solution for monitoring surface synoptic scale $A_{T}$ and $C_{T}$. It also enables the first demonstration of observation-based synoptic scale $A_{T}$ and $C_{T}$ temporal mixing in the Amazon plume for 2010-2016, complete with a robust estimation of their uncertainty.
\end{abstract}

\section{Introduction}

The oceans play an important role in absorbing carbon (e.g. Sabine et al., 2004), and the increase in $\mathrm{CO}_{2}$ emitted into the atmosphere as a result of anthropogenic activities has resulted in an increase in $\mathrm{CO}_{2}$ uptake by the oceans (Caldeira and Wickett, 2005; Sabine et al., 2004; Takahashi et al., 2009). This long-term absorption results in a shift in ocean carbonate chemistry, which has the potential to alter biogeochemical cycles and ecosystem function in the future (Raven et al.,
2005; Kroeker et al., 2013). As a result of the decrease in ocean $\mathrm{pH}$ arising from these shifts (often termed Ocean Acidification), this change in ocean carbonate chemistry has received increasing scientific and political attention over the past decade. This has led to questions about the magnitude and importance of spatial and temporal ocean carbon variability, as well as how to monitor ongoing change at global and regional scales. To-date, carbonate system monitoring has been primarily from ship- and field-based observations that provide relatively disparate and sparse datasets of carbonate chemistry parameters in both

\footnotetext{
* Corresponding author.

E-mail address: peland@pml.ac.uk (P.E. Land).
} 
space and time. To expand capabilities, state-of-the-art autonomous in situ tools are needed (Byrne, 2014). Recent advances include pH sensors on biogeochemical floats (e.g. Johnson et al., 2017), and sensors to observe multiple carbonate system parameters in situ are now in development (Bushinsky, 2019). One such advancement is utilizing Earth Observation (EO) satellites to provide wider spatial and temporal coverage of surface carbonate chemistry observations, with the aim of detecting features and characterizing dynamics that are difficult to resolve using in situ datasets (Land et al., 2015; Salisbury et al., 2015; Fine et al., 2017). Currently, there are just two satellites in orbit that are specifically designed to support global carbon cycle research (The US NASA Orbiting Carbon Observatory OCO-2 (Osterman et al., 2016), and the Chinese Tansat; Yang et al., 2018), but their focus is to observe and monitor atmospheric $\mathrm{CO}_{2}$. However, there is a suite of ocean observing satellite sensor datasets that could be used, through exploitation of empirical relationships, to provide measures of marine carbonate chemistry parameters that include total alkalinity $\left(\mathrm{A}_{\mathrm{T}}\right)$, total dissolved inorganic carbon $\left(\mathrm{C}_{\mathrm{T}}\right)$, partial pressure of $\mathrm{CO}_{2}$ in seawater $\left(\mathrm{pCO}_{2}\right)$ and pH (Gledhill et al., 2009).

These four primary variables allow the ocean carbonate system to be investigated. In principle, knowledge of at least two of these four, in conjunction with temperature, salinity and pressure, allows the remaining variables to be calculated (Dickson and Riley, 1978). The relationships between these variables are principally driven by thermodynamics; temperature, pressure and salinity are therefore fundamentally associated with the carbonate system (Dickson et al., 2007). Furthermore, salinity is a significant driver of the ionic composition of seawater and hence has a strong relationship with $A_{T}$ (Millero et al., 1998). In addition to these physical controls on the carbonate system, the variables can be influenced by other chemical processes, including weathering and carbonate formation/dissolution (Friis et al., 2003), and biological processes such as primary production, respiration, calcification and remineralization (Smith and Key, 1975). With this knowledge it is possible to determine how the carbonate system variables vary in relation to factors such as temperature, salinity, nitrate or chlorophyll (the latter two as proxies for biological processes). These relationships take the form of empirical algorithms, which can be used to derive the respective carbonate system variable, and have been developed within a number of global and regional studies, e.g. Takahashi and Sutherland, 2013; Lee et al. (2006); Lee et al. (2000); Sasse et al. (2013); Cai et al. (2010); Lefèvre et al. (2010); Bonou et al. (2016); see Land et al. (2015) and references therein.

Although initially developed from in situ datasets, these empirical algorithms could potentially be forced with inputs from other sources, such as satellite observations or climatologies to yield observationbased carbon system observations. Here we conduct a first assessment of four global algorithms for $\mathrm{A}_{\mathrm{T}}$ and three for $\mathrm{C}_{\mathrm{T}}$, utilizing different combinations of satellite, interpolated in situ and climatology datasets as input. We then evaluate their output using independent in situ measurements of $\mathrm{A}_{\mathrm{T}}$ and $\mathrm{C}_{\mathrm{T}}$. As a baseline comparison, we evaluate estimates of $A_{T}$ and $C_{T}$ from an Earth System model. In addition to the global algorithms, we also assess three regional $A_{T}$ and two regional $C_{T}$ algorithms. We aim to demonstrate algorithm suitability both globally and for regional case studies (the Caribbean, the Amazon plume and the Bay of Bengal), and to assess the performance of these different approaches, particularly the relevance of satellite datasets, in being able to reproduce the in situ patterns of these two carbonate system variables in surface waters.

\section{Materials and methods}

\subsection{Published algorithms}

The four global algorithms used here for $\mathrm{A}_{\mathrm{T}}$ are from Lee et al. (2006) (hereafter referred to as L06), Takahashi and Sutherland (2013) (hereafter referred to as TS13) and Sasse et al. (2013) (domain-based and global algorithms, hereafter referred to as S13 and S13g). L06 separated the oceans into five domains and used an optimal polynomial fit to $A_{T}$ data, resulting in a relationship with sea surface salinity (SSS) and sea surface temperature (SST) for each region. TS13 took this a step further using a larger combination of datasets to separate the oceans into 33 domains. Instead of using SST and SSS, TS13 assessed potential alkalinity relationship with SSS, where potential alkalinity is $A_{T}$ plus nitrate concentration $\left(\mathrm{NO}_{3}\right)$, which corrects $\mathrm{A}_{\mathrm{T}}$ for the effect of changes in $\mathrm{NO}_{3}$ caused by net community utilization. Sasse et al. (2013) used multiple linear regression to relate domain and global $\mathrm{A}_{\mathrm{T}}$ to SST, SSS, $\mathrm{SSS}^{2}$, dissolved oxygen (DO), silicate $(\mathrm{Si})$ and phosphate $\left(\mathrm{PO}_{4}\right)$. The three regional $\mathrm{A}_{\mathrm{T}}$ algorithms are all linear relationships with SSS using data from the Amazon plume and Caribbean (Cai et al., 2010; Lefèvre et al., 2010). Two other regional algorithms (Cooley et al., 2007; Ternon et al., 2000) were considered, but were not used here as results differed only marginally from Lefèvre et al. (2010) and they used much of the same training data.

The three global $C_{T}$ algorithms that we used are from Lee et al. (2000) (hereafter referred to as L00) and Sasse et al. (2013) (domainbased and global algorithms, hereafter referred to as S13 and S13g). L00 found $\mathrm{C}_{\mathrm{T}}$ normalized to salinity 35 on the Practical Salinity Scale and year 1990, $\left(\mathrm{nC}_{\mathrm{T}}=\mathrm{C}_{\mathrm{T}} \times 35 / \mathrm{SSS}+\right.$ (year -1990 between $30^{\circ} \mathrm{S}$ and $30^{\circ} \mathrm{N}$ )), to be strongly correlated with SST and $\mathrm{NO}_{3}$, and conducted optimal polynomial fitting for $\mathrm{C}_{\mathrm{T}}$ to domain data, giving a total of 12 regionally parameterized equations. Sasse et al. (2013) used multiple linear regression to relate domain and global $\mathrm{C}_{\mathrm{T}}$ to SST, SSS, DO, $\mathrm{NO}_{3}$, $\mathrm{Si}$ and $\mathrm{PO}_{4}$. The two regional $\mathrm{C}_{\mathrm{T}}$ algorithms are both linear relationships with SSS using data from the Amazon plume (Lefèvre et al., 2010; Bonou et al., 2016). The same two regional studies as for $A_{T}$ (Cooley et al., 2007; Ternon et al., 2000) were considered for $C_{T}$, but again results differed only marginally from those of Lefèvre et al. (2010) and so they were not used.

In all cases, extrapolation of algorithms beyond the range for which they were calibrated is questionable, and this is especially true of nonlinear algorithms. To avoid this, we did not use any algorithm outside its specified range of applicability, or more than one SSS unit or SST degree outside its calibration range if a range of applicability is not specified. Table 1 summarises the algorithm choices and dependences. Additional details on each empirical relationship for all algorithms are provided in Supporting Information Text S1.

\subsection{Round-robin comparison}

Four case study regions were used in a round-robin comparison of the algorithms: the global ocean, the Caribbean $\left(14^{\circ} \mathrm{N}\right.$ to $30^{\circ} \mathrm{N}, 90^{\circ} \mathrm{W}$ to

Table 1

Summary of algorithms, their dependencies and the region for which they were originally developed. AT $=$ Total Alkalinity, $\mathrm{CT}=$ Dissolved Inorganic Carbon; SSS $=$ Sea Surface Salinity, SST $=$ Sea Surface Temperature, DO $=$ Dissolved Oxygen, $\mathrm{N}=$ nitrate, $\mathrm{Si}=$ silicate, $\mathrm{P}=$ phosphate.

\begin{tabular}{|c|c|c|c|c|}
\hline Product & Name & Dependencies & Reference & Region \\
\hline AT & TS13 & SSS, N & $\begin{array}{l}\text { Takahashi and Sutherland } \\
\text { (2013) }\end{array}$ & Global \\
\hline AT & L06 & SSS, SST & Lee et al. (2006) & Global \\
\hline AT & S13 & SSS, SST, DO, Si, P & Sasse et al., (2013) & Global \\
\hline AT & S13g & SST, SSS, DO, Si, P & Sasse et al., (2013) & Global \\
\hline AT & & SSS & Lefèvre et al. (2010) & APR \\
\hline AT & & SSS & Cai et al. (2010) & GCR, APR \\
\hline CT & L00 & SSS, SST, N & Lee et al. (2000) & Global \\
\hline CT & S13 & $\begin{array}{l}\text { SST, SSS, DO, N, Si, } \\
\text { P }\end{array}$ & Sasse et al., (2013) & Global \\
\hline CT & S13g & $\begin{array}{l}\text { SST, SSS, DO, N, Si, } \\
\text { P }\end{array}$ & Sasse et al., (2013) & Global \\
\hline CT & & SSS & Lefèvre et al. (2010) & APR \\
\hline CT & & SSS & Bonou et al. (2016) & APR \\
\hline
\end{tabular}


$60^{\circ} \mathrm{W}$ for compatibility with Gledhill et al. (2008)), the Amazon plume $\left(2^{\circ} \mathrm{S}\right.$ to $22^{\circ} \mathrm{N}, 70^{\circ} \mathrm{W}$ to $\left.32^{\circ} \mathrm{W}\right)$, and the Bay of Bengal $\left(5^{\circ} \mathrm{N}\right.$ to $24^{\circ} \mathrm{N}, 78^{\circ} \mathrm{E}$ to $96^{\circ} \mathrm{E}$, using the Bay of Bengal International Hydrographic Office Sea Area (International Hydrographic Organization, 1953)). These case studies were chosen as areas that are potentially challenging for this assessment and are discussed in more detail in Land et al. (2015). The Amazon region was chosen to enclose the region of freshening contiguous with the mouth of the Amazon with any monthly satellite SSS $<35$, with an eastern boundary at $32^{\circ} \mathrm{W}$, beyond which rain freshening dominates the Amazon plume (Ibánhez et al., 2016). The region defined also includes many points with SSS $>35$. To investigate the effect of these points, we also defined a low-salinity Amazon region where data with in situ SSS $>35$ were excluded.

Each algorithm was tested using input data for each forcing factor (SSS, SST, $\mathrm{NO}_{3}, \mathrm{DO}, \mathrm{Si}$ and/or $\mathrm{PO}_{4}$ ) from a range of data sources and all possible combinations of inputs were included in the round-robin comparison. The input data for the empirical algorithms were:

1) Monthly mean satellite observed data from the Soil Moisture and Ocean Salinity (SMOS) satellite [SSS 2010-2017 CATDS-IFR-CECv02] (Reul et al., 2015), the Aquarius satellite [SSS 2011-2015, Version 5] (Le Vine et al., 2014), and the Climate Change Initiative (CCI) [SST 1991-2010] (Merchant et al., 2012);

2) In situ re-analysis data from the Coriolis Ocean Re-Analysis (CORA v4.3) database [SSS, SST 1990-2012] (Cabanes et al., 2013);

3) Monthly climatology data from the World Ocean Atlas (WOA) dataset [SSS, SST, nitrate, DO, Si, $\mathrm{PO}_{4}$ ] (Garcia et al., 2014a; Garcia et al., 2014b; Locarnini et al., 2013; Zweng et al., 2013); Note that WOA 'nitrate' is actually nitrate + nitrite $\left(\mathrm{NO}_{3}+\mathrm{NO}_{2}\right)$. However, $\mathrm{NO}_{2}$ typically has a concentration at least an order of magnitude lower than $\mathrm{NO}_{3}$, and so this discrepancy is neglected. The previously mentioned baseline comparison dataset were $\mathrm{A}_{\mathrm{T}}$ and $\mathrm{C}_{\mathrm{T}}$ output from the HadGEM2-ES global Earth system model, 1972-2020 (Jones et al., 2011) (hereafter referred to as HG2).

All data were binned spatially to a $1^{\circ} \times 1^{\circ}$ grid and temporally to monthly intervals (henceforth referred to as monthly data). The multiyear CORA, satellite and HG2 data were also each combined to form monthly climatologies (climatological data). Only $1^{\circ} \times 1^{\circ}$ grid cells with at least two values were used to calculate climatological data. Details of all of these input datasets are provided in Table 2.

The binned $\mathrm{A}_{\mathrm{T}}$ or $\mathrm{C}_{\mathrm{T}}$ from each algorithm and input, herein referred to as 'output', and the binned output from HG2 were all evaluated (validated) against binned in situ data of the respective carbonate parameter. Data from the Global Data Analysis Project Version 2 (GLODAPv2, 1972-2013) (Olsen et al., 2016) were the primary in situ evaluation (validation) data used for both $\mathrm{A}_{\mathrm{T}}$ and $\mathrm{C}_{\mathrm{T}}$ evaluations, along with some additional regional in situ data (see Table 3). The GLODAPv2 dataset is a community compiled, merged and internally consistent global dataset. In all cases of in situ data, the mean measurement in the top $10 \mathrm{~m}$ water depth was used.

Following (Sasse et al., 2013), we attempted to separate the effects of terrigenous influences and sediment resuspension on the biogeochemistry of coastal waters from open ocean carbonate chemistry by calculating the minimum depth within each cell using the GEBCO_08 1min grid (www.gebco.net/data_and_products/gridded_bathymetry_
Table 3

In situ carbonate chemistry datasets used for evaluating the outputs. All datasets for each variable were combined into one dataset that was averaged monthly on a $1^{\circ} \times 1^{\circ}$ grid. The Bhadury et al. coastal data are from a sampling station located on the coast of India at $21^{\circ} 40^{\prime} 40.6^{\prime \prime} \mathrm{N}, 88^{\circ} 9^{\prime} 19.2^{\prime \prime} \mathrm{E}$, shown in Fig. 1 of Choudhury et al. (2015) (Station 3). The Findlay et al. research cruise data are from cruises off the Svalbard and Greenland coasts, $78^{\circ} 53^{\prime}-59^{\prime} \mathrm{N}, 11^{\circ}$ $42^{\prime}-12^{\circ} 27^{\prime} \mathrm{E}$ and $70^{\circ} 14-49^{\prime} \mathrm{N}, 22^{\circ} 4-32^{\prime} \mathrm{W}$ respectively.

\begin{tabular}{llll}
\hline & Dataset name & Time period & References \\
\hline AT, CT & GLODAPv2 & $1970-2013$ & Olsen et al. (2016) \\
AT, CT & OWS Mike & $2001-2007$ & Findlay et al., 2008 \\
AT & Bhadury et al. coastal data & 2014 & Choudhury et al. (2015) \\
AT, CT & Findlay et al. research cruise & $2012-2014$ & [Findlay pers. comm.] \\
\hline
\end{tabular}

data/gebco_one_minute_grid/, downloaded on December 14th, 2009) and repeating our analysis using only grid cells with minimum depth greater than $500 \mathrm{~m}$. Again following (Sasse et al., 2013), we further separated terrigenous effects by calculating the minimum distance from the nearest coast within each cell using (https://oceancolor.gsfc.nasa. gov/docs/distfromcoast/, downloaded on October 5th, 2018) and repeated the analysis using only grid cells with both a minimum depth greater than $500 \mathrm{~m}$ and a minimum distance greater than $300 \mathrm{~km}$. All three sets of results are included in Supplementary Information, but only data with both masks applied are presented here.

\subsection{Statistical measures}

\subsubsection{Data uncertainties}

The GLODAPv2 analysis (Olsen et al., 2016), the chosen reference validation dataset, includes an estimate of the maximum bias that exists between different instruments determined via a crossover analysis as 4 and $6 \mu \mathrm{mol} \mathrm{kg}^{-1}$ for $\mathrm{C}_{\mathrm{T}}$ and $\mathrm{A}_{\mathrm{T}}$ respectively. Whereas a full uncertainty budget (i.e. a type A uncertainty estimate (BIPM, 2008) comprising a combination of bias and standard deviation of all measurements against a traceable standard) is not provided. Therefore in the absence of all components of the uncertainty information we assume nominal uncertainties of $0.5 \%$ for all in situ $\mathrm{A}_{\mathrm{T}}$ and $\mathrm{C}_{\mathrm{T}}$ (Bockmon et al., 2015). It should be noted that due to relatively recent improvements in quality control we would expect older in situ measurements to have greater uncertainties and more recent measurements to have lesser, though this variation is difficult to quantify. For interest, the GLODAPv2 bias estimate stated above for a mean global $\mathrm{A}_{\mathrm{T}}$ of $2450 \mu \mathrm{mol} \mathrm{kg}^{-1}$ gives a potential bias around $0.2 \%$. Uncertainties in the input (forcing) data (SST, SSS, $\mathrm{NO}_{3}$ and $\mathrm{HG} 2 \mathrm{~A}_{\mathrm{T}}$ and $\mathrm{C}_{\mathrm{T}}$ ) were not included in our analysis, since these are unknown for many of the input datasets. For interest only, the reported uncertainty in SMOS SSS is below \pm 0.3 for a 30 day average over a $100 \times 100 \mathrm{~km}$ open ocean area (Reul et al., 2012, 2014) and can be below \pm 0.2 for an 18 day average (Boutin et al., 2018) or in certain evaporation-dominated regions, and for Aquarius SSS it is \pm 0.17 for a monthly average over a $150 \times 150 \mathrm{~km}$ open ocean area (Lagerloef et al., 2015). Uncertainty in CCI SST is between \pm 0.1 and $\pm 0.15 \mathrm{~K}$ (Merchant et al., 2014). However, we could find no uncertainty estimates for the CORA, WOA or HG2 datasets, and it would be inconsistent to apply uncertainties to some inputs and not others. We discuss the impact of this approach within Section 4.2.

Table 2

Datasets used as inputs to the empirical algorithms. SSS = sea surface salinity, SST = sea surface temperature, DO = dissolved oxygen.

\begin{tabular}{lllll}
\hline & Type & Name & Time period & References \\
\hline SSS & Satellite & SMOS (CATDS v2) & $2010-2014$ & Reul and Team (2015) \\
SSS & Satellite & Aquarius & $2011-2014$ & Le Vine et al. (2014) \\
SST & Satellite & ESA SST CCI & $1992-2010$ & Merchant et al. (2012) \\
SSS, SST & Re-analysis & CORA v4.0 & $1990-2012$ & Cabanes et al. (2013) \\
SSS, SST, DO, N, P, Si & Climatology & WOA & $1970-2012$ & (Garcia et al., 2014a; Garcia et al., 2014b; Locarnini et al., 2013; Zweng et al., 2013)
\end{tabular}


(A)
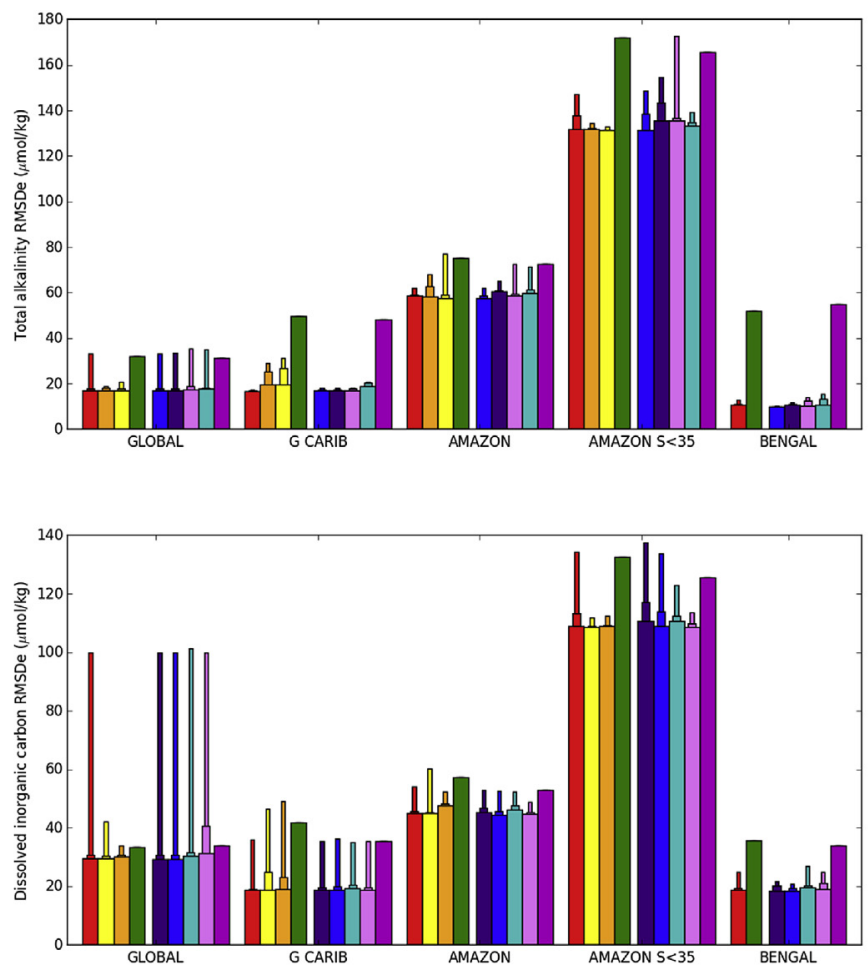

Fig. 1. Estimated regional weighted RMSD (RMSDe) for each SSS source. Data are grouped by region, then by whether the input data are climatological (left group) or monthly (right group), then by SSS source. All regional output $s$ using a given SSS source are considered, and the wide bar shows the lowest RMSDe of these, the half-width bar shows the median RMSDe and the thin bar shows the highest RMSDe. SSS sources in each group are shown in order of global lowest RMSDe. (A) AT results; (B) CT results.
The published algorithm uncertainties (as stated in the corresponding reference) for each algorithm were propagated through to the algorithm outputs. Following standard propagation methods (Taylor, 1997), in situ and algorithm uncertainties were combined assuming that they were uncorrelated (a sum of squares analysis), allowing weighted statistics to be calculated, with each data point weighted by the inverse of the sum of squared uncertainties.

\subsubsection{Evaluating output accuracy}

Output mean $\left(\overline{\mathrm{x}}_{\mathrm{m}}\right)$, standard deviation $\left(\sigma_{\mathrm{m}}\right)$ and in situ carbonate data mean $\left(\bar{x}_{\mathrm{d}}\right)$ and standard deviation $\left(\sigma_{\mathrm{d}}\right)$ were calculated for each assessment, as well as root-mean-square-difference (RMSD), mean absolute difference (MAD), bias and point-to-point correlation (R) between output and the evaluation (GLODAPv2) in situ data. As a check, each of these statistics is presented both weighted and unweighted. Unweighted and weighted RMSD values were usually within about $10 \%$, except in the case of global $\mathrm{A}_{\mathrm{T}}$ using the TS13 algorithm, which includes regions with very different algorithm errors. Weighted statistics are used hereafter.

A potential problem with comparing outputs in this way is that different outputs overlap with different evaluation in situ data. Consider the plausible situation in which all outputs perform poorly in coastal waters. All else being equal, an output that is not evaluated using coastal in situ data will produce better statistics than one that is. Therefore, to compare like with like, in each region we considered outputs in pairs, for a given pair calculating RMSD for each of the two outputs using only in situ evaluation matchups shared by both outputs. Each output is given a 'score' of RMSD / RMSD ${ }_{\min }, 1$ for the lower RMSD and $\geq 1$ for the other. This is repeated for all possible pairs, then each output is given a 'final score' equal to the mean of all of its scores. To convert this to an estimate of RMSD, we chose a representative output as that with the lowest value of (weighted final score / number of matchups), i.e. the output with the best combination of performance and coverage. The weighted RMSD of this output (RMSD $\mathrm{Rep}_{\text {rep }}$ ) was left unchanged and all other output weighted RMSDs in the region were set

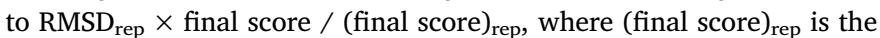
final score of the representative output; this measure is henceforth referred to as RMSDe. Output results can be compared directly within a region, but comparison of output RMSDe between regions or carbonate parameters should be treated with caution. The above calculations could equally be done using MAD in place of RMSD, though we have not done this here.

\subsubsection{Evaluating optimal combinations of output elements and importances}

To calculate the relative importance of different combinations of output elements (algorithms and/or data inputs) to the output comparison results, we calculated the best RMSDe when a given combination is excluded from all outputs, and divided it by the overall best RMSDe to give an RMSDe ratio. For example, the most effective single exclusion, with an RMSDe ratio of 1.022 (i.e. a $2.2 \%$ difference), is $A_{T}$ using climatological CORA SSS in the Bay of Bengal. The best $13 \mathrm{~A}_{\mathrm{T}}$ outputs in the Bay of Bengal all use climatological CORA SSS. Conversely, the best output also uses monthly CCI SST but the second best uses WOA SST, so excluding monthly CCI SST has much less effect. Excluding WOA SST has no effect, since the best output is still the one using monthly CCI SST. Having excluded climatological CORA SSS, the next 14 best $\mathrm{A}_{\mathrm{T}}$ outputs all use the TS13 algorithm, so excluding climatological CORA SSS and TS13 has the largest effect among pairs of exclusions in this region. All possible combinations of exclusions were considered, ranked in order of number of elements excluded, then by RMSDe ratio.

The resulting comprehensive list is rather hard to read and interpret. To simplify, we created subsets of exclusions objectively considered as most significant. Criteria used were that the RMSDe ratio was greater than 1.01, the exclusions were either all SSS and/or SST inputs or all algorithms, and RMSDe ratio exceeded that of a subset of exclusions by $>0.1 \%$. For example, excluding TS13 and SMOS SSS would not qualify, and excluding SMOS and Aquarius SSS would only qualify if its RMSDe ratio were greater than excluding only SMOS and only Aquarius by $>0.1 \%$.

\subsubsection{Comparing between carbonate parameters}

To compare between carbonate parameters in each region, we only considered in situ evaluation data points where both $\mathrm{A}_{\mathrm{T}}$ and $\mathrm{C}_{\mathrm{T}}$ values 
Table 4

Coverage, RMSDe and bias of the lowest RMSDe output for each SSS source in each region and carbonate parameter. Note that coverage is compared to all possible matchups, so recent SSS sources such as satellites have relatively low coverage.

\begin{tabular}{|c|c|c|c|}
\hline SSS Input & Coverage (\%) & $\begin{array}{l}\text { RMSDe }(\mu \mathrm{mol} \mathrm{kg} \text { - } \\
\text { 1) }\end{array}$ & $\begin{array}{l}\text { BIAS ( } \mu \mathrm{mol} \mathrm{kg-} \\
1)\end{array}$ \\
\hline
\end{tabular}

\section{GLOBAL AT $(\mathrm{N}=6019)$}

In situ SD for comparison

SSS_CORA

SSS_AQUARIUS

SSS_SMOS

HG2

SSS_CORA_CLIM

SSS_WOA_CLIM

SSS_SMOS_CLIM

SSS_AQUARIUS_CLIM 93

HG2 CLIM 100

G CARIB AT $(\mathrm{N}=55)$

In situ SD for comparison

SSS_CORA

SSS_AQUARIUS

SSS_SMOS

HG2

SSS_CORA_CLIM

SSS WOA_CLIM

SSS_SMOS_CLIM

SSS_AQUARIUS_CLIM

HG2_CLIM

81
17
17
17
32
17
17
18
18
31

AMAZON AT ( $\mathrm{N}=108)$

In situ SD for comparison

SSS_SMOS

SSS_AQUARIUS

SSS_CORA

HG 2

SSS_CORA_CLIM

SSS_SMOS_CLIM

SSS_AQUARIUS_CLIM 100

SSS WOA CLIM 100

HG2_CLIM 100

AMAZON $\mathrm{S}<35$ AT $(\mathrm{N}=15)$

In situ SD for comparison

SSS_SMOS

SSS_CORA

SSS_AQUARIUS

HG2

SSS CORA CLIM

SSS_AQUARIUS_CLIM

SSS_WOA_CLIM

SSS SMOS CLIM

HG2_CLIM

BENGAL AT $(\mathrm{N}=23)$

In situ SD for comparison

SSS_CORA

HG2

SSS_CORA_CLIM

SSS_SMOS_CLIM

SSS WOA CLIM

SSS_AQUARIUS_CLIM 100

HG2_CLIM

GLOBAL CT $(\mathrm{N}=6689)$

In situ SD for comparison

SSS_CORA

SSS_SMOS

SSS_AQUARIUS

HG2

SSS_WOA_CLIM

SSS_CORA_CLIM

SSS_AQUARIUS_CLIM

SSS_SMOS_CLIM

HG2_CLIM

G CARIB CT $(\mathrm{N}=53)$

In situ SD for comparison

SSS_CORA

SSS_SMOS

SSS_AQUARIUS

HG2
$-5$

$-17$

$-2$

$-5$

$-16$

13

13
17

19

20

50

17

17

17

19

48

68

58

58

59

75

57

59

60

60

73

115

132

132

132

172

132

133

135

136

166

16

11

52

10

11

11

55

69

30

30

30

33

29

29

30

31

34

18

19

19

19
Table 4 (continued)

\begin{tabular}{|c|c|c|c|}
\hline SSS Input & Coverage (\%) & $\begin{array}{l}\text { RMSDe }(\mu \mathrm{mol} \mathrm{kg-} \\
\text { 1) }\end{array}$ & $\begin{array}{l}\text { BIAS ( } \mu \mathrm{mol} \mathrm{kg-} \\
1)\end{array}$ \\
\hline SSS_WOA_CLIM & 100 & 19 & 9 \\
\hline SSS_CORA_CLIM & 100 & 19 & 10 \\
\hline SSS_SMOS_CLIM & 100 & 19 & 10 \\
\hline SSS_AQUARIUS_CLIM & 100 & 19 & 8 \\
\hline HG2_CLIM & 100 & 36 & 45 \\
\hline \multicolumn{4}{|l|}{ AMAZON CT $(\mathrm{N}=155)$} \\
\hline In situ SD for comparison & & 53 & \\
\hline SSS_CORA & 85 & 45 & 3 \\
\hline SSS_SMOS & 21 & 45 & 3 \\
\hline SSS_AQUARIUS & 8 & 48 & 0 \\
\hline HG2 & 100 & 57 & 33 \\
\hline SSS_CORA_CLIM & 100 & 45 & 0 \\
\hline SSS_SMOS_CLIM & 100 & 45 & 0 \\
\hline SSS_WOA_CLIM & 100 & 45 & -2 \\
\hline SSS_AQUARIUS_CLIM & 100 & 46 & -1 \\
\hline HG2_CLIM & 100 & 53 & 30 \\
\hline \multicolumn{4}{|c|}{ AMAZON S < 35 CT $(\mathrm{N}=17)$} \\
\hline In situ SD for comparison & & 96 & \\
\hline SSS_SMOS & 18 & 109 & 100 \\
\hline SSS_AQUARIUS & 18 & 109 & 108 \\
\hline SSS_CORA & 94 & 109 & 45 \\
\hline $\mathrm{HG} 2$ & 100 & 132 & 118 \\
\hline SSS_SMOS_CLIM & 100 & 109 & 3 \\
\hline SSS_CORA_CLIM & 100 & 109 & 44 \\
\hline SSS_AQUARIUS_CLIM & 100 & 111 & 21 \\
\hline SSS_WOA_CLIM & 100 & 111 & 45 \\
\hline HG2_CLIM & 100 & 125 & 108 \\
\hline \multicolumn{4}{|l|}{ BENGAL CT $(\mathrm{N}=24)$} \\
\hline In situ SD for comparison & & 10 & \\
\hline SSS_CORA & 96 & 19 & 16 \\
\hline $\mathrm{HG} 2$ & 100 & 36 & 51 \\
\hline SSS_CORA_CLIM & 100 & 18 & -12 \\
\hline SSS_WOA_CLIM & 100 & 18 & -11 \\
\hline SSS_SMOS_CLIM & 100 & 19 & -14 \\
\hline SSS_AQUARIUS_CLIM & 100 & 20 & -17 \\
\hline HG2_CLIM & 100 & 34 & 48 \\
\hline
\end{tabular}

existed. For each data point and parameter, all outputs producing valid output were considered and the one with the best regional final score was chosen, noting the output-in situ difference for this output. The regional RMSD of each parameter was then calculated from the differences at all data points in the region.

\section{Results}

Results are summarized in Fig. 1A and B, showing RMSDe for $A_{T}$ and $\mathrm{C}_{\mathrm{T}}$, Table 4 , showing statistics of the lowest-RMSDe output for each SSS source plus HG2 output in each region, and Table 5, showing selected importances. Fig. 2 to 4 contain plots of output versus evaluation (GLODAPv2) in situ $\mathrm{A}_{\mathrm{T}}, \mathrm{C}_{\mathrm{T}}$ and SSS data, with points with depth < $500 \mathrm{~m}$ and $>300 \mathrm{~km}$ from the coast labeled. Alternative versions of Fig. 1A and B for differing masks are shown in Fig. S1. Supporting data (Land et al., 2019) consist of three data collections corresponding to all data, minimum depth $500 \mathrm{~m}$, and minimum depth $500 \mathrm{~m}$ plus minimum distance to coast $300 \mathrm{~km}$; matchup data, output statistics, details of output score calculations, spatial data results, importances of exclusions and the comparisons between carbonate parameters (also included in Supplementary Information) are included.

Generally there is little to choose between the SSS sources (reanalysed in situ or satellite) apart from HG2, which performs less well in all regions, or between monthly and climatological SSS sources. The main differences in performance are between algorithms and between regions, but there is no clearly superior algorithm.

\subsection{Total alkalinity $\left(A_{T}\right)$}

See Table 4 for detailed results. Globally, the best RMSDe values of 
Table 5

Selected importances of exclusions for each carbonate parameter and region. A source of SSS or SST can be monthly (M), climatological (C) or all (no prefix). Importances are the percentage increase in RMSDe as a result of excluding all the listed inputs or algorithms. Only exclusions mentioned in the text are listed here, more complete lists can be found in (Land et al., 2019).

\begin{tabular}{|c|c|c|}
\hline Exclusions & Importance (\%) & Notes \\
\hline \multicolumn{3}{|l|}{$\left(\right.$ GLOBAL $\left.A_{T}\right)$} \\
\hline TS13,L06,S13g & 3.1 & Only leaves S13,HG2 \\
\hline TS13,L06,S13g,S13 & 85 & Only leaves HG2 \\
\hline CORA,M SMOS,M Aquarius,WOA SSS & 3.0 & $\begin{array}{l}\text { Only leaves C SMOS,C } \\
\text { Aquarius }\end{array}$ \\
\hline CORA,SMOS,M Aquarius,WOA SSS & 4.1 & $\begin{array}{l}\text { Only leaves C } \\
\text { Aquarius }\end{array}$ \\
\hline \multicolumn{3}{|l|}{$\left(G\right.$ CARIB $\left.A_{T}\right)$} \\
\hline CORA,WOA,C SMOS SSS & 13 & $\begin{array}{l}\text { Only leaves M } \\
\text { SMOS,Aquarius }\end{array}$ \\
\hline TS13,L06,S13g,Cai10 & 2.9 & Only leaves S13,HG2 \\
\hline TS13,L06,S13g,Cai10,S13 & 286 & Only leaves HG2 \\
\hline CORA,WOA,C Aquarius,C SMOS SSS & 16 & $\begin{array}{l}\text { Only leaves M } \\
\text { SMOS,M Aquarius }\end{array}$ \\
\hline $\begin{array}{l}\text { CORA,WOA,Aquarius,C SMOS SSS } \\
\left(\text { AMAZON } A_{T} \text { ) }\right.\end{array}$ & 18 & Only leaves M SMOS \\
\hline TS13,L06,S13,S13g & 2.6 & \\
\hline TS13,L06,S13,S13g,Cai10 & 4.4 & $\begin{array}{l}\text { Only leaves } \\
\text { Lefevre10,HG2 }\end{array}$ \\
\hline SMOS,CORA,M Aquarius SSS & 4.0 & $\begin{array}{l}\text { Only leaves C } \\
\text { Aquarius,WOA SSS }\end{array}$ \\
\hline TS13,L06,S13,S13g,Cai10,Lefevre10 & 26 & Only leaves HG2 \\
\hline $\begin{array}{l}\text { SMOS,CORA,Aquarius SSS } \\
\left(\text { AMAZON S }<35 \mathrm{~A}_{\mathrm{T}} \text { ) }\right.\end{array}$ & 5.1 & Only leaves WOA SSS \\
\hline M SMOS,M Aquarius SSS,M CCI SST & 2.5 & $\begin{array}{l}\text { All monthly satellite } \\
\text { data }\end{array}$ \\
\hline M SMOS,Aquarius SSS,M CCI SST & 3.2 & \\
\hline SMOS,Aquarius SSS,M CCI SST & 4.6 & \\
\hline M SMOS,Aquarius,CORA SSS & 2.9 & \\
\hline $\begin{array}{l}\text { TS13,L06,S13,S13g,Cai10,Lefevre10 } \\
\left(\text { BENGAL } \mathrm{A}_{\mathrm{T}}\right)\end{array}$ & 26 & Only leaves HG2 \\
\hline C CORA SSS & 2.2 & \\
\hline C CORA,C SMOS SSS & 5.1 & \\
\hline C CORA,C SMOS,WOA SSS & 6.4 & $\begin{array}{l}\text { Only leaves M } \\
\text { CORA,C Aquarius }\end{array}$ \\
\hline TS13,L06,S13 & 3.7 & Only leaves S13g,HG2 \\
\hline TS13,L06,S13,S13g & 517 & Only leaves HG2 \\
\hline CORA,C SMOS,WOA SSS & 8.1 & $\begin{array}{l}\text { Only leaves C } \\
\text { Aquarius }\end{array}$ \\
\hline \multicolumn{3}{|l|}{$\left(\right.$ GLOBAL $\left.\mathrm{C}_{\mathrm{T}}\right)$} \\
\hline LO0 & 3.6 & \\
\hline $\mathrm{L} 00, \mathrm{~S} 13 \mathrm{~g}$ & 5.3 & \\
\hline L00,S13g,S13 & 14 & Only leaves HG2 \\
\hline CORA,WOA,M SMOS SSS & 3.6 & \\
\hline CORA,WOA,M SMOS,M Aquarius SSS & 4.4 & $\begin{array}{l}\text { Only leaves C SMOS,C } \\
\text { Aquarius }\end{array}$ \\
\hline $\begin{array}{l}\text { CORA,WOA,Aquarius,M SMOS SSS } \\
\left(\text { G CARIB } C_{T} \text { ) }\right.\end{array}$ & 7.7 & Only leaves C SMOS \\
\hline $\mathrm{L} 00, \mathrm{~S} 13$ & 73 & $\begin{array}{l}\text { Only leaves S13g and } \\
\text { HG2 }\end{array}$ \\
\hline L00,S13,S13g & 90 & Only leaves HG2 \\
\hline SMOS,CORA,WOA,M Aquarius SSS & 3.9 & $\begin{array}{l}\text { Only leaves C } \\
\text { Aquarius }\end{array}$ \\
\hline \multicolumn{3}{|l|}{$\left(\right.$ AMAZON C $\mathrm{T}_{\mathrm{T}}$ ) } \\
\hline L00,S13,Bonou16,Lefevre10 & 2.1 & $\begin{array}{l}\text { Only leaves } \mathrm{S} 13 \mathrm{~g} \text { and } \\
\text { HG2 }\end{array}$ \\
\hline L00,S13,Bonou16,Lefevre10,S13g & 19 & Only leaves HG2 \\
\hline SMOS,CORA,WOA SSS & 3.6 & Only leaves Aquarius \\
\hline SMOS,CORA,C Aquarius,WOA SSS & 7.0 & $\begin{array}{l}\text { Only leaves } \mathrm{M} \\
\text { Aquarius }\end{array}$ \\
\hline \multicolumn{3}{|l|}{$\left(\right.$ AMAZON S $\left.<35 \mathrm{C}_{\mathrm{T}}\right)$} \\
\hline L00,S13,Bonou16,Lefevre10 & 2.2 & $\begin{array}{l}\text { Only leaves } \mathrm{S} 13 \mathrm{~g} \text { and } \\
\text { HG2 }\end{array}$ \\
\hline L00,S13,Bonou16,Lefevre10,S13g & 15 & Only leaves HG2 \\
\hline SMOS,Aquarius SSS,M CCI SST & 2.6 & $\begin{array}{l}\text { Only leaves } \\
\text { CORA,WOA SSS }\end{array}$ \\
\hline $\begin{array}{l}\text { SMOS,Aquarius,CORA SSS,M CCI SST } \\
\left(\text { BENGAL } \mathrm{C}_{\mathrm{T}} \text { ) }\right.\end{array}$ & 4.9 & Only leaves WOA SSS \\
\hline S13 & 2.1 & \\
\hline S13,S13g & 9.9 & \\
\hline
\end{tabular}

Table 5 (continued)

\begin{tabular}{lll}
\hline Exclusions & Importance (\%) & Notes \\
\hline C CORA,WOA SSS & 2.1 & \\
L00,S13,S13g & 83 & Only leaves HG2 \\
CORA,WOA SSS & 3.6 & \\
CORA,C SMOS,WOA SSS & 5.9 & \\
\hline
\end{tabular}

about $17 \mu \mathrm{mol} \mathrm{kg}^{-1}$ are substantially lower than the SD of the global coverage in situ data used for the evaluation $\left(81 \mu \mathrm{mol} \mathrm{kg}^{-1}\right)$, and in the Amazon and Bay of Bengal they are slightly lower (RMSDe of 55 compared to a SD of 68 , and RMSDe of 11 compared to a SD of $16 \mu \mathrm{mol} \mathrm{kg}^{-1}$, respectively), but in the Greater Caribbean and lowsalinity Amazon the RMSDe are higher than the SD, meaning that none of the tested combinations of algorithms and inputs is accurate enough to distinguish natural variations in $\mathrm{A}_{\mathrm{T}}$ in these latter two regions.

\subsection{1. $A_{T}$ algorithm and input importances}

See Table 5 for details. Globally, S13 performs slightly less well (higher RMSDe) than other algorithms, as do climatological satellite inputs. In the Greater Caribbean, monthly SMOS and Aquarius and climatological Aquarius SSS perform significantly less well. In the Amazon, the Lefevre et al. (2010) algorithm and climatological Aquarius and WOA SSS perform less well. In the low-salinity Amazon, monthly SMOS and Aquarius and monthly CCI SST perform best. In the Bay of Bengal, climatological CORA SSS performs best and climatological Aquarius performs significantly less well.

\subsection{2. $A_{T}$ summary}

For all case study regions and with respect to these empirical outputs, satellite SSS can reproduce in situ measured $\mathrm{A}_{\mathrm{T}}$ from the GLODAPv2 evaluation dataset with performance (RMSDe) comparable to, or better than, the re-analysed in situ data derived inputs for SSS, and the satellite based $\mathrm{A}_{\mathrm{T}}$ is always better than $\mathrm{HG} 2 \mathrm{~A}_{\mathrm{T}}$ estimates. Globally HG2 performance is about $85 \%$ worse than the best SSS driven outputs, but this reduces to $15-20 \%$ in the Amazon plume. Monthly Aquarius and SMOS observations provide a credible solution to monitoring synoptic scale global and regional $\mathrm{A}_{\mathrm{T}}$, though in some challenging regions (Greater Caribbean and low-salinity Amazon plume) none of the tested methods are sufficiently accurate to resolve natural variability.

RMSDe in the Amazon plume is higher than the global RMSDe, reflecting the larger regional standard deviation in the in situ data due to the large gradients around the river flow, and RMSDe in the Amazon with SSS $<35$ is higher than in the wider Amazon, but the relative performance of SSS inputs is similar.

Excluding the Amazon plume and HG2, the best outputs have bias less than $5 \mu \mathrm{mol} \mathrm{kg} \mathrm{kg}^{-1}$, or $0.2 \%$ of the global mean $\mathrm{A}_{\mathrm{T}}$ (of $2450 \mu \mathrm{mol} \mathrm{kg}^{-1}$ ) which is similar to the estimated evaluation dataset in situ nominal uncertainty of $0.5 \%$ (Bockmon et al., 2015) and the interannual variability of $A_{T}$ observed at oceanic sites such as at the Hawaiian Ocean Time-series station (HOT; $\pm 6 \mu \mathrm{mol} \mathrm{kg}^{-1}$ ) (Brix et al., 2004), but lower than the seasonal variability observed at oceanic sites ( 20 to $30 \mu \mathrm{mol} \mathrm{kg}{ }^{-1}$ at both the Bermuda Atlantic Time-series Study (BATS) (Bates et al., 2012) and the European time series station (ESTOC) (Santana-Casiano et al., 2007). This seasonal variability at BATS and ESTOC is also greater than the best global RMSDe of $17 \mu \mathrm{mol} \mathrm{kg}^{-1}$. In the Amazon plume, of the monthly SSS sources only SMOS has low bias $\left(2 \mu \mathrm{mol} \mathrm{kg}{ }^{-1}\right)$, and in the low-salinity Amazon plume, all SSS sources have bias greater than $19 \mu \mathrm{mol} \mathrm{kg}^{-1}$. These results highlight that these methods (of using satellite observations or reanalysed in situ dataset as input to empirical algorithms) can obtain measures of $\mathrm{A}_{\mathrm{T}}$ that are not significantly biased relative to the evaluation in situ measurements, except in regions of strong spatiotemporal variability. It also shows that these methods are capable of distinguishing the seasonal variability at long-term time series sites, though 


\section{A)}
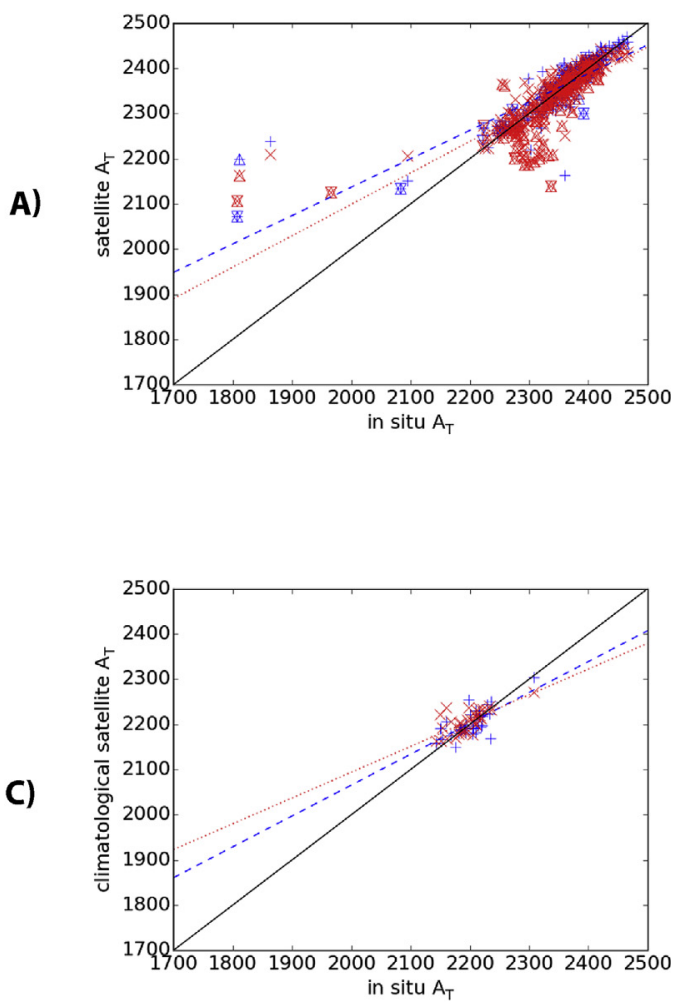

B)

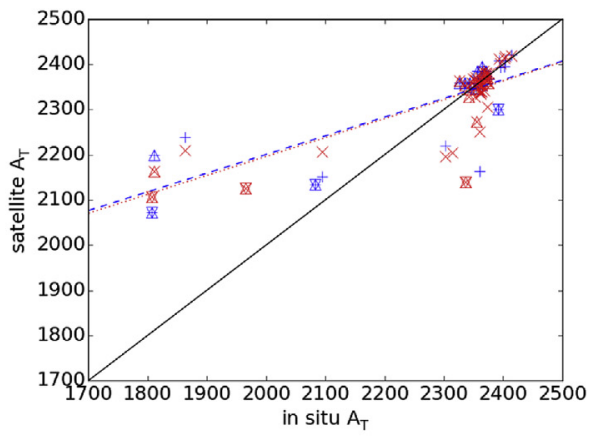

D)

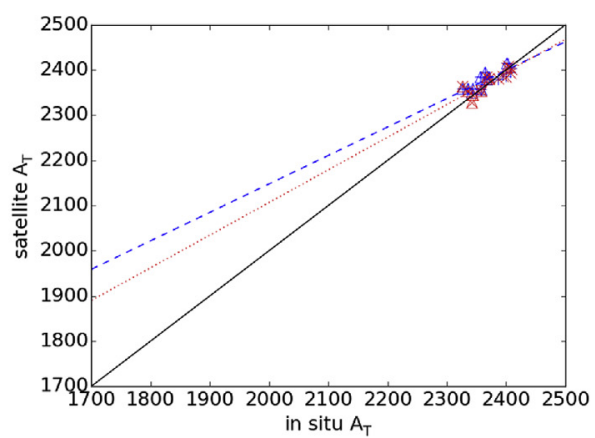

Fig. 2. Comparison of AT estimated using monthly satellite SSS with in situ measured AT. (A) global; (B) Amazon plume; (C) Bay of Bengal using climatological satellite SSS; (D) Greater Caribbean. The algorithm is (Takahashi et al., 2013) with climatological WOA nitrate. Red crosses use SMOS SSS, blue plusses use Aquarius. Points with down-pointing triangles have depth less than $500 \mathrm{~m}$, those with up-pointing triangles are less than $300 \mathrm{~km}$ from the nearest coast. Regressions use all data.

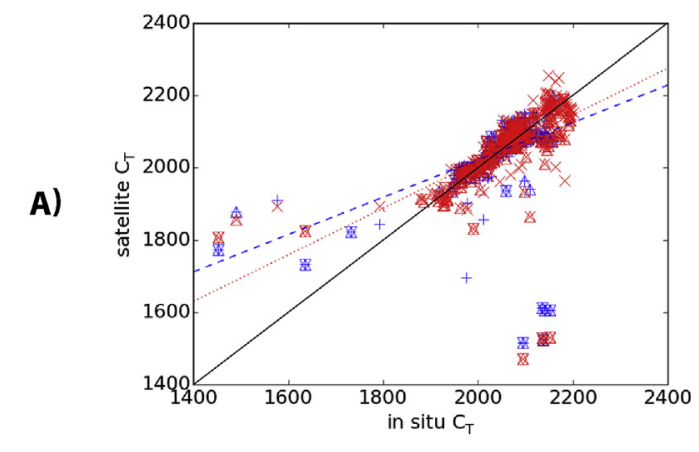

B)
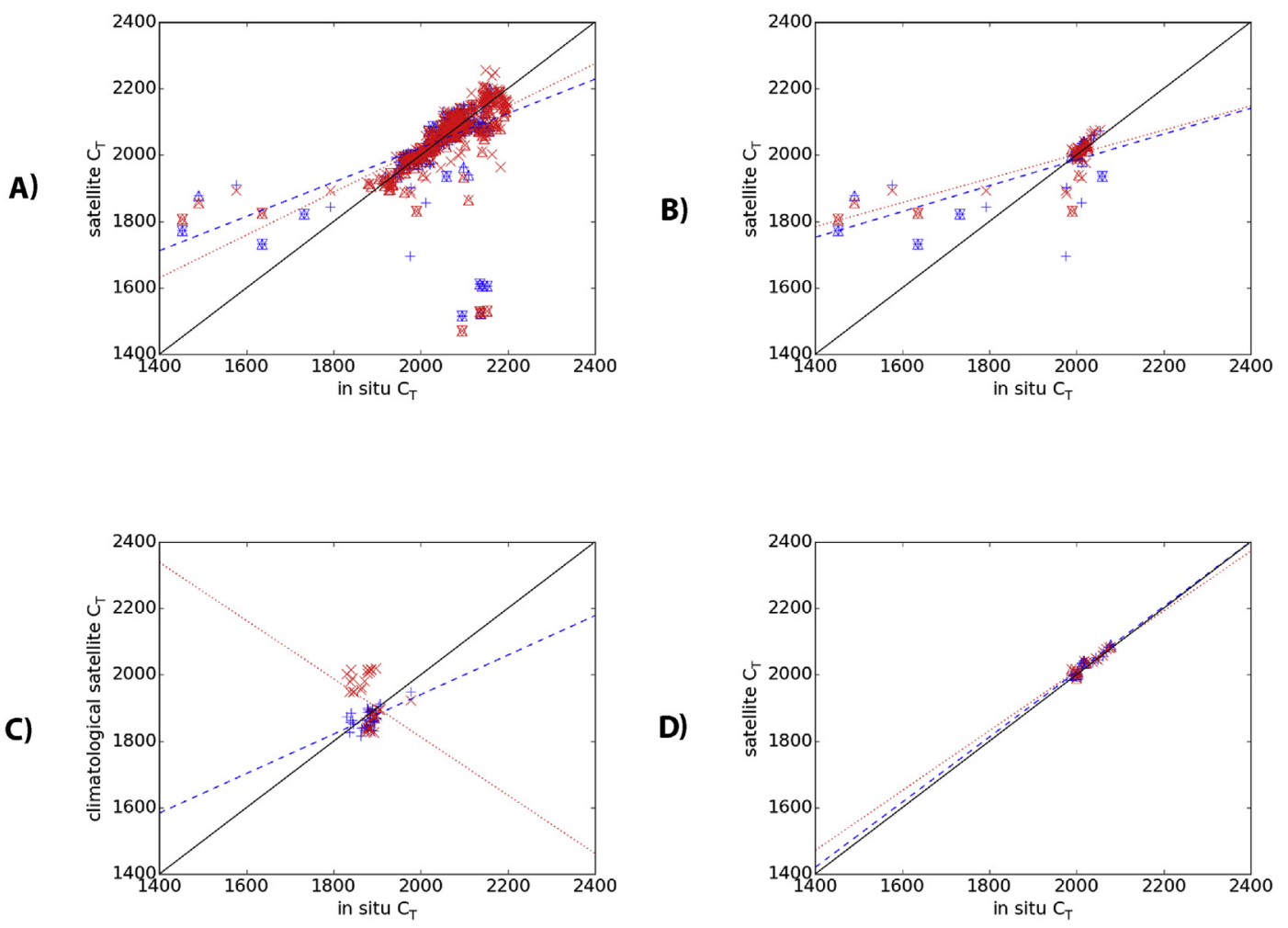

Fig. 3. Comparison of CT estimated using monthly satellite SSS with in situ measured CT. (A) global; (B) Amazon plume; (C) Bay of Bengal using climatological satellite SSS; (D) Greater Caribbean. The algorithm is (Lee et al., 2000) with climatological WOA SST and nitrate. Red crosses use SMOS SSS, blue plusses use Aquarius. Points with down-pointing triangles have depth less than $500 \mathrm{~m}$, those with up-pointing triangles are less than $300 \mathrm{~km}$ from the nearest coast. Regressions use all data. 
A)
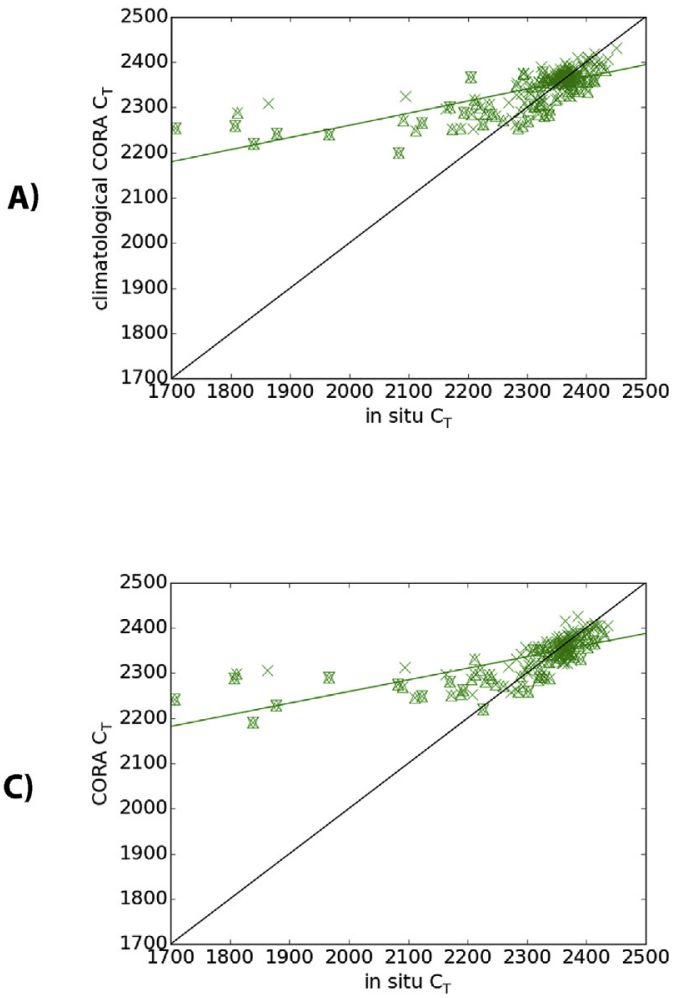

B)

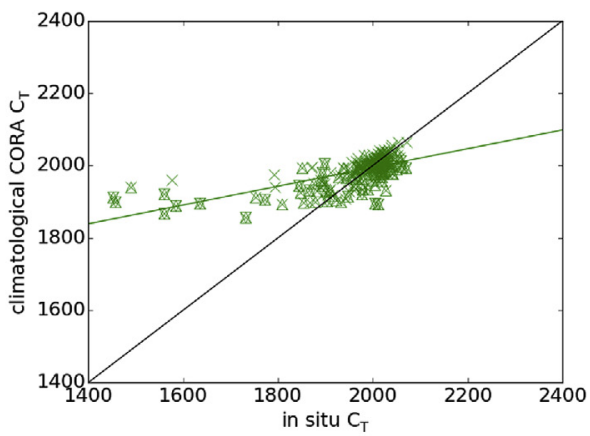

D)

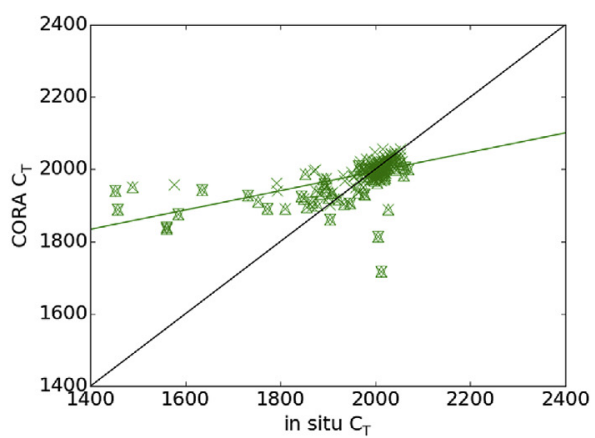

Fig. 4. Comparison of AT and CT estimated from CORA (interpolated in situ) SSS with in situ measured values in the Amazon plume. (A) AT comparison using climatological CORA SSS; (B) CT comparison using climatological CORA SSS; (C) AT comparison using monthly CORA SSS; (D) CT comparison using monthly CORA SSS. The AT algorithm is (Takahashi and Sutherland, 2013) with climatological WOA nitrate, and the CT algorithm is (Lee et al., 2000) with climatological CORA SST and climatological WOA nitrate. Points with down-pointing triangles have depth less than $500 \mathrm{~m}$, those with up-pointing triangles are less than $300 \mathrm{~km}$ from the nearest coast. Regressions use all data.

A)

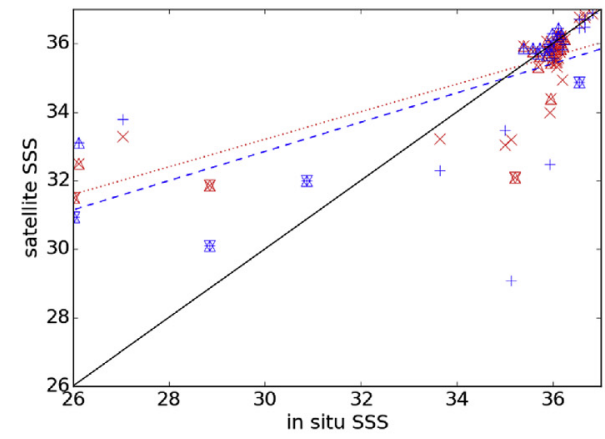

C)

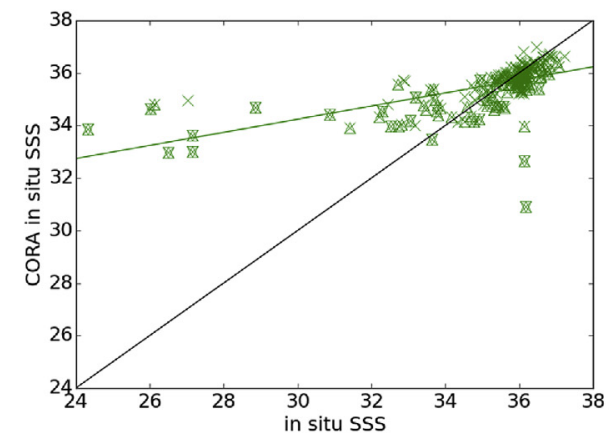

B)

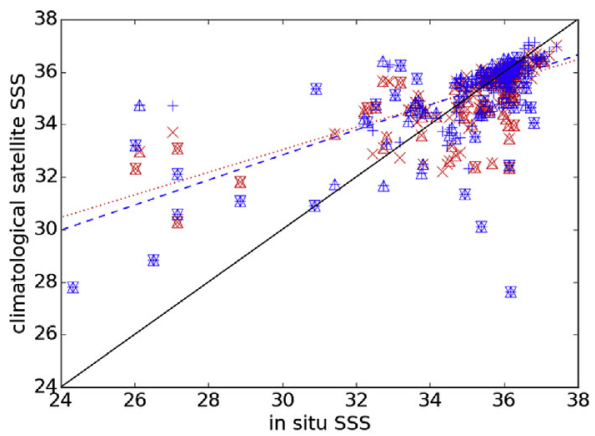

D)

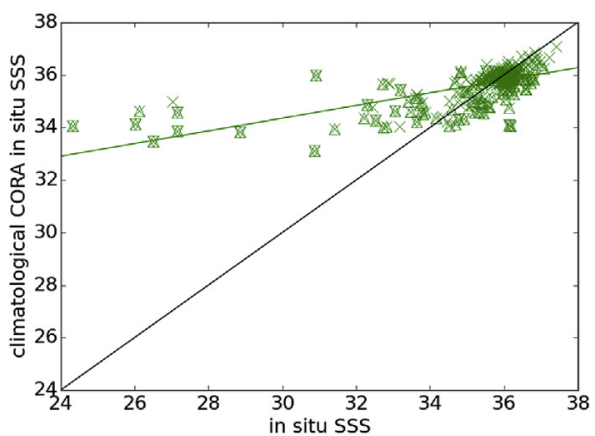

Fig. 5. Comparison of satellite and CORA SSS with in situ measured SSS in the Amazon plume. (A) monthly SMOS (red crosses) and Aquarius (blue plusses); (B) climatological SMOS and Aquarius; (C) monthly CORA; (D) climatological CORA. Points with down-pointing triangles have depth less than 500 m, those with uppointing triangles are less than $300 \mathrm{~km}$ from the nearest coast. Regressions use all data. 

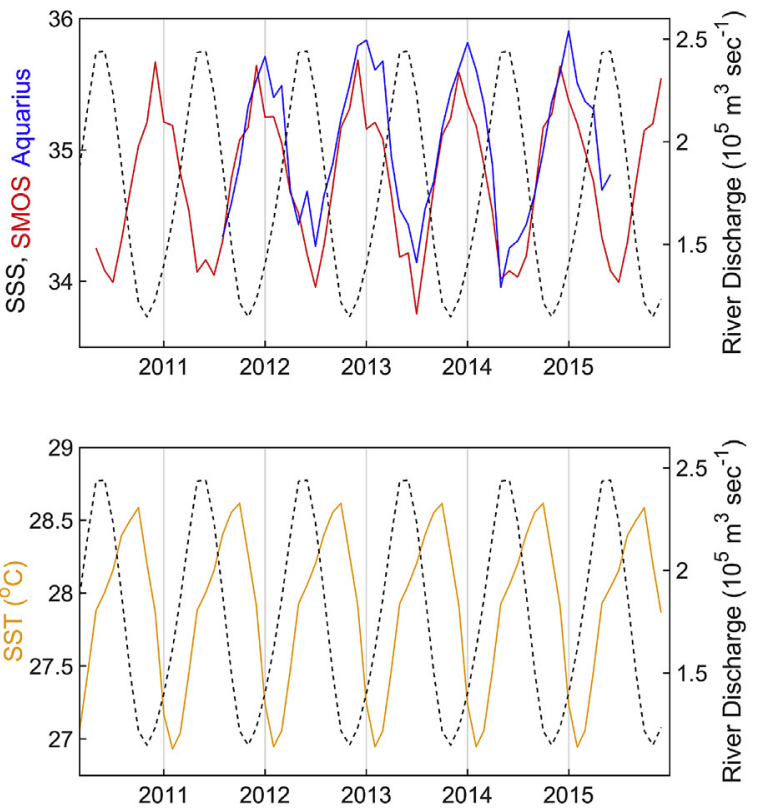

(C)

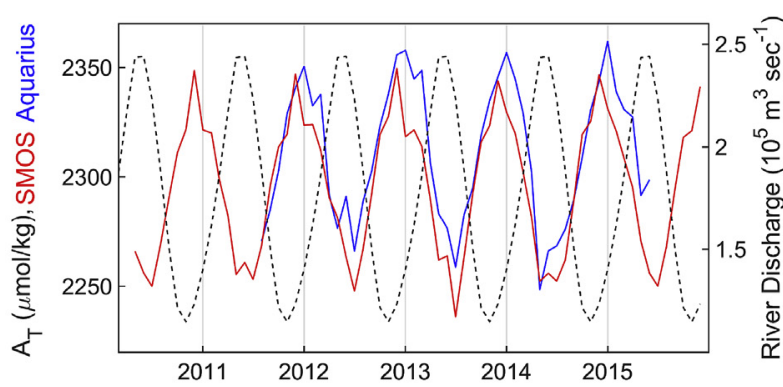

(D)

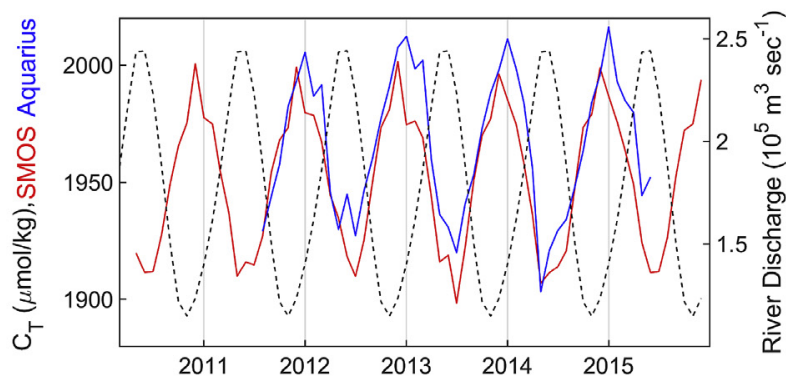

Fig. 6. Time series of Amazon plume discharge and averaged satellite observations between 2010 and 2016. Monthly observations were average over the area $0^{\circ}-15^{\circ} \mathrm{N}, 45^{\circ}-62^{\circ} \mathrm{W}$. Dashed black lines are climatological discharge at the Obidos gauge, red use SMOS SSS and blue use Aquarius SSS. In months containing both SMOS and Aquarius data, only cells with valid data in both are used. (A) monthly SMOS and Aquarius SSS; (B) climatological CORA (orange) SST; (C) AT using the TS13 algorithm and WOA nitrate, with monthly SMOS and Aquarius SSS; (D) CT using the L00 algorithm, CORA SST climatology and WOA nitrate, with monthly SMOS and Aquarius SSS.

not the interannual variability at HOT.

\subsection{Total dissolved inorganic carbon $\left(C_{T}\right)$}

See Table 4 for detailed results. Globally, the best RMSDe values of 29-30 $\mu \mathrm{mol} \mathrm{kg}^{-1}$ are considerably higher than the equivalent global $\mathrm{A}_{\mathrm{T}}$ RMSDe values, but still substantially lower than the SD of the global in situ evaluation dataset $\left(69 \mu \mathrm{mol} \mathrm{kg}{ }^{-1}\right)$, and in the Amazon and Greater Caribbean they are similar (RMSDe 45 compared to SD 53 and RMSDe 19 compared to SD $18 \mu \mathrm{mol} \mathrm{kg}^{-1}$, respectively), but in the low-salinity
Amazon and Bay of Bengal they are higher, meaning that no combination of algorithms and inputs is accurate enough to distinguish natural variations in $\mathrm{C}_{\mathrm{T}}$ in these latter two regions.

\subsection{1. $C_{T}$ algorithm and input importances}

See Table 5 for details. Globally, L00 and S13g perform better (lower RMSDe) than other algorithms, as do CORA, WOA and monthly SMOS SSS inputs. In the Greater Caribbean, the S13g algorithm performs very poorly and climatological Aquarius SSS performs less well than other SSS inputs. In the Amazon, the S13g algorithm and Aquarius SSS perform less well. In the low-salinity Amazon, the $\mathrm{S13g}$ algorithm performs less well, while SMOS, Aquarius and monthly CCI SST perform best. In the Bay of Bengal, the S13 and S13g algorithms perform considerably better than other algorithms and CORA and WOA SSS perform better than other SSS sources.

\subsection{2. $C_{T}$ summary}

Similar to $A_{T}$, satellite inputs for SSS can reproduce the $C_{T}$ data (from the GLODAPv2 evaluation dataset) with similar ability, and sometimes better than using re-analysed or climatology in situ derived SSS inputs, except for Aquarius in the Amazon plume (Fig. 1B), and always better than HG2 $\mathrm{C}_{\mathrm{T}}$ estimates. Global HG2 performance is only about $14 \%$ worse than the best SSS driven outputs, but this increases to over $80 \%$ in the Bay of Bengal and Greater Caribbean. As with $A_{T}$, monthly SMOS and Aquarius observations provide a credible solution to monitoring synoptic scale global and in some cases regional $\mathrm{C}_{\mathrm{T}}$. Best RMSDe values are higher for $\mathrm{C}_{\mathrm{T}}$ than $\mathrm{A}_{\mathrm{T}}$ globally and in the Greater Caribbean and Bay of Bengal, but lower in both Amazon plume regions. Again, in some challenging regions (low-salinity Amazon plume and Bay of Bengal), none of the tested methods are sufficiently accurate to reproduce natural variations.

Bias in the $\mathrm{C}_{\mathrm{T}}$ outputs is generally greater and more variable than that in the $A_{T}$ outputs, except in the Amazon plume where non-HG2 monthly and climatological bias is uniformly less than $3 \mu \mathrm{mol} \mathrm{kg}{ }^{-1}$. The smallest bias among the best global monthly outputs is monthly CORA with $-9 \mu \mathrm{mol} \mathrm{kg}{ }^{-1}$, in the Greater Caribbean monthly SMOS and Aquarius have bias of 3 and $4 \mu \mathrm{mol} \mathrm{kg}^{-1}$ respectively, monthly outputs in the low-salinity Amazon are all strongly biased, the smallest being CORA with $45 \mu \mathrm{mol} \mathrm{kg}{ }^{-1}$, and in the Bay of Bengal monthly CORA has bias of $16 \mu \mathrm{mol} \mathrm{kg}^{-1}$ while climatological datasets (WOA, CORA, SMOS) have lower bias $\left(-11,-12,-14 \mu \mathrm{mol} \mathrm{kg}^{-1}\right.$ respectively). For comparison, the in situ nominal uncertainty of $0.5 \%$ (Bockmon et al., 2015) at the global average $C_{T}$ of $1900 \mu \mathrm{mol} \mathrm{kg}^{-1}$ would be $9.5 \mu \mathrm{mol} \mathrm{kg}{ }^{-1}$, the inter-annual variability of $\mathrm{nC}_{\mathrm{T}}$ is $\pm 4 \mu \mathrm{mol} \mathrm{kg} \mathrm{kg}^{-1}$ at HOT and $\pm 8 \mu \mathrm{mol} \mathrm{kg}^{-1}$ at ESTOC (Brix et al., 2004, Santana-Casiano et al., 2007), while the seasonal amplitude of $\mathrm{nC}_{\mathrm{T}}$ at $\mathrm{HOT}$ is $15 \mu \mathrm{mol} \mathrm{kg}{ }^{-1}$ (Brix et al., 2004) and those of $C_{T}$ at ESTOC and BATS are 20-30 and $40-50 \mu \mathrm{mol} \mathrm{kg}^{-1}$, respectively (Santana-Casiano et al., 2007; Bates et al., 2012). The biases in these outputs are also comparable to the systematic biases found by Lee et al. (2000) when comparing algorithm derived $\mathrm{nC}_{\mathrm{T}}$ to $\mathrm{nC}_{\mathrm{T}}$ calculated from $\mathrm{A}_{\mathrm{T}}$ and $\mathrm{pCO}_{2}$ data $\left(-3\right.$ to $\left.+15 \mu \mathrm{mol} \mathrm{kg}{ }^{-1}\right)$. Thus, these results highlight that some of the outputs evaluated can obtain measures of $\mathrm{C}_{\mathrm{T}}$ that are not significantly biased relative to the in situ evaluation measurements, though overall uncertainties may be high relative to the variability at these long-term monitoring sites.

\section{3. $A_{T}$ and $C_{T}$ algorithm biases}

In the Amazon Plume, the best output was strongly correlated with the evaluation in situ $\mathrm{A}_{\mathrm{T}}$ or $\mathrm{C}_{\mathrm{T}}$, but with a slope significantly different from 1 (Figs. 2B and 3B). Replacing monthly satellite SSS with monthly or climatological CORA SSS (re-analysed and interpolated in situ) produces similar biases (Fig. 4), suggesting that the cause of the bias is not specific to satellite SSS or monthly data.

A possible explanation of this bias would be that the algorithm is not 


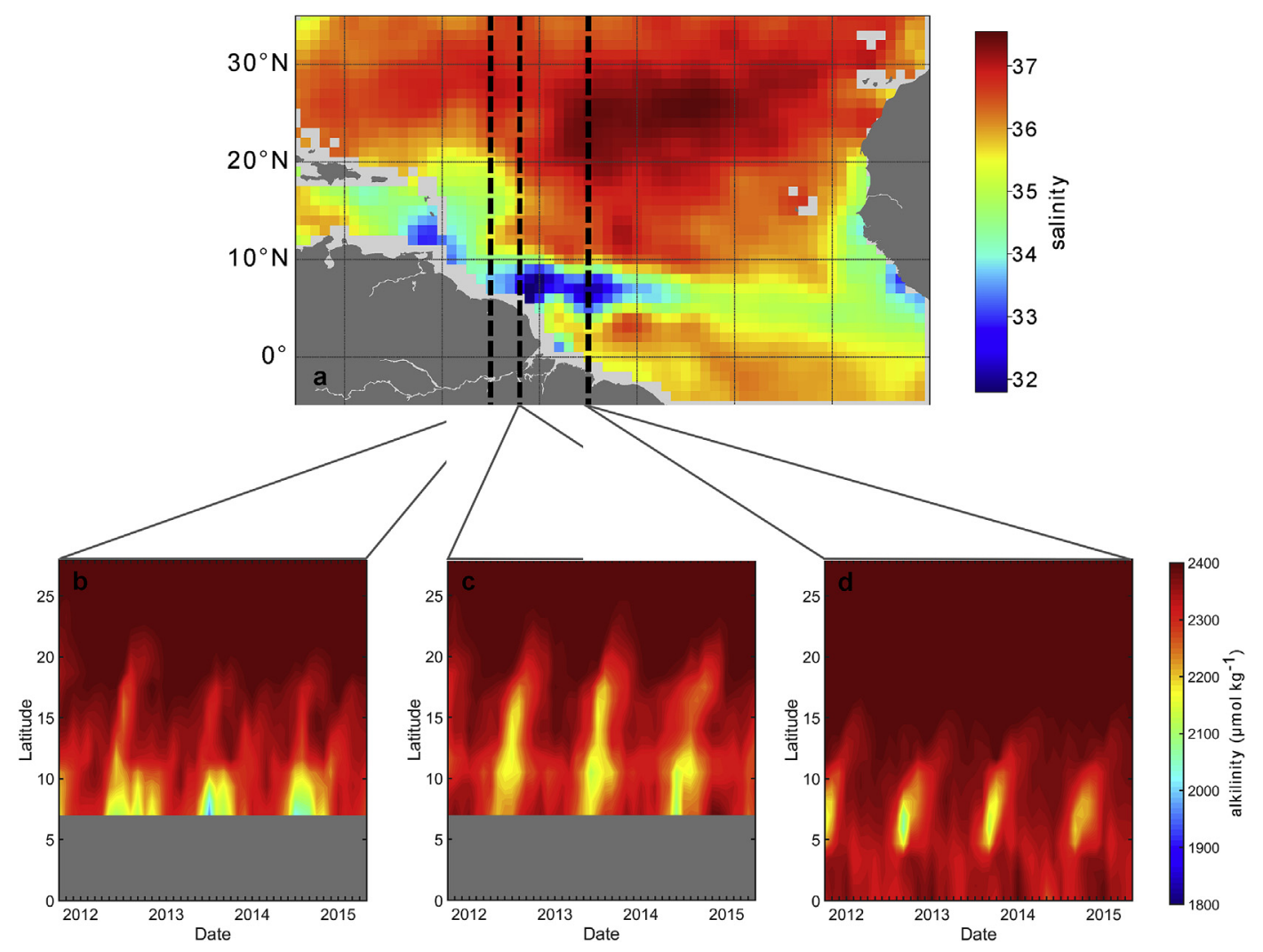

Fig. 7. Aquarius derived synoptic scale observations of AT in $\mu$ mol kg-1 for the Amazon Plume between August 2011 and June 2015 using the TS13 algorithm and WOA nitrate, with monthly SMOS and Aquarius SSS: (a) AT in August 2011 showing the bifurcation of the plume; (b) Hovmöller time series plot for 55 $5^{\circ}$; (c) Hovmöller time series plot for $52^{\circ} \mathrm{W}$ and (d) Hovmöller time series plot for $45^{\circ} \mathrm{W}$.

capturing the two endmember mixing from the river with zero salinity and some finite, but significant $\mathrm{A}_{\mathrm{T}}$ and $\mathrm{C}_{\mathrm{T}}$. However, the regional algorithms for the Amazon plume implicitly include the river endmember, as they are based on measurements that include low and high salinity values, and each published algorithm finds a strongly linear relationship between salinity and $\mathrm{A}_{\mathrm{T}}$ or $\mathrm{C}_{\mathrm{T}}$. Since the bias using these algorithms is similar to that using the global algorithms, we can conclude that the endmember issue is not the main reason for the bias.

Another possible explanation of the bias would be sampling of water with low SSS, $A_{T}$ and $C_{T}$ in regions with high spatial and temporal SSS variability, as found in the Amazon plume and particularly within the low salinity Amazon plume region. Satellite and CORA data represent an average over at best one grid cell (about $10^{4}$ square kilometers at the equator) and one month (or the same month in a range of years in the case of climatological data), while an in situ measurement samples a very small volume of water and is almost instantaneous. The effect of this averaging is to remove variability that occurs on smaller spatial and temporal scales. For example, low in situ salinity in the Amazon plume may be caused by small eddies or filaments of river water not resolvable at the grid cell scale, or by interannual variations in the plume extent. In this situation, extreme evaluation in situ values will consistently be matched with outputs driven by satellite and CORA data that are closer to the large-scale and long-term mean. If the salinity distribution is strongly one-tailed, as in the Amazon plume, and the cause of anomalies is consistently unresolved by the averaged data, the in situ evaluation data will consistently give lower salinity than the averaged data, as observed here (Fig. 5). This issue is likely to be one cause of the large biases evident in all output results (re-analysed in situ and satellite input derived) for the low salinity Amazon region.

A third possible explanation for the bias arises from fundamental differences between the in situ measurements used to calibrate the original algorithms and the satellite salinity observations used herein as input to the algorithms. Satellite SSS observations represent the conditions in the top $10 \mathrm{~mm}$ of the water (Boutin et al., 2013), whereas in situ SSS observations are typically sampled from $\geq 1 \mathrm{~m}$ below the surface. This can result in geophysical sources of variation between satellite and in situ salinity, which are linked to vertical salinity stratification, and these features are prevalent in regions of rain, oceanic fronts and river outflow (Boutin et al., 2013, 2016; Drucker and Riser, 2014). For example, salinity gradients created by freshwater plumes can complicate the comparison of satellite and in situ salinity measurements; a difference of $2-5 \mathrm{pss} \mathrm{m}^{-1}$ has been observed across the halocline in the Amazon plume (Lentz and Limeburner, 1995). Plumes can also cause horizontal salinity gradients with spatial scales smaller than the footprint of the satellite radiometers. Typical horizontal SSS gradients for the plumes from the Amazon (Lentz and Limeburner, 1995) or Congo (Chao et al., 2015) exceed $0.2 \mathrm{pss} \mathrm{km}^{-1}$ and extend more than $250 \mathrm{~km}$ from the river mouth. Therefore, in the vicinity of a river plume, a spatially sparse array of in situ sensors can exhibit very different SSS variability from that observed by a satellite sensor, even if the measurements are all coincident. Similarly, high-frequency SSS variations (e.g. tidal effects) can be undersampled by satellite-derived SSS products due to the relatively long revisit time of the satellite (2-3 days for SMOS and 7 days for Aquarius). Accounting for the depthrelated differences should increase the accuracy of the outputs, and a rigorous treatment might adapt the theory currently used to reconcile in situ and satellite SST (Merchant et al., 2014). We therefore recommend that the satellite SSS community consider investigating this theory for SSS.

In the absence of a rigorously tested explanation for these biases, and to demonstrate the potential gain from reducing them, we simply note that linear regression of the best output against the evaluation in situ $\mathrm{A}_{\mathrm{T}}$ and $\mathrm{C}_{\mathrm{T}}$ reduces the RMSD (actual, not estimated) in the low salinity Amazon plume region from 215 to $48 \mu \mathrm{mol} \mathrm{kg}^{-1}$ (a $77 \%$ 

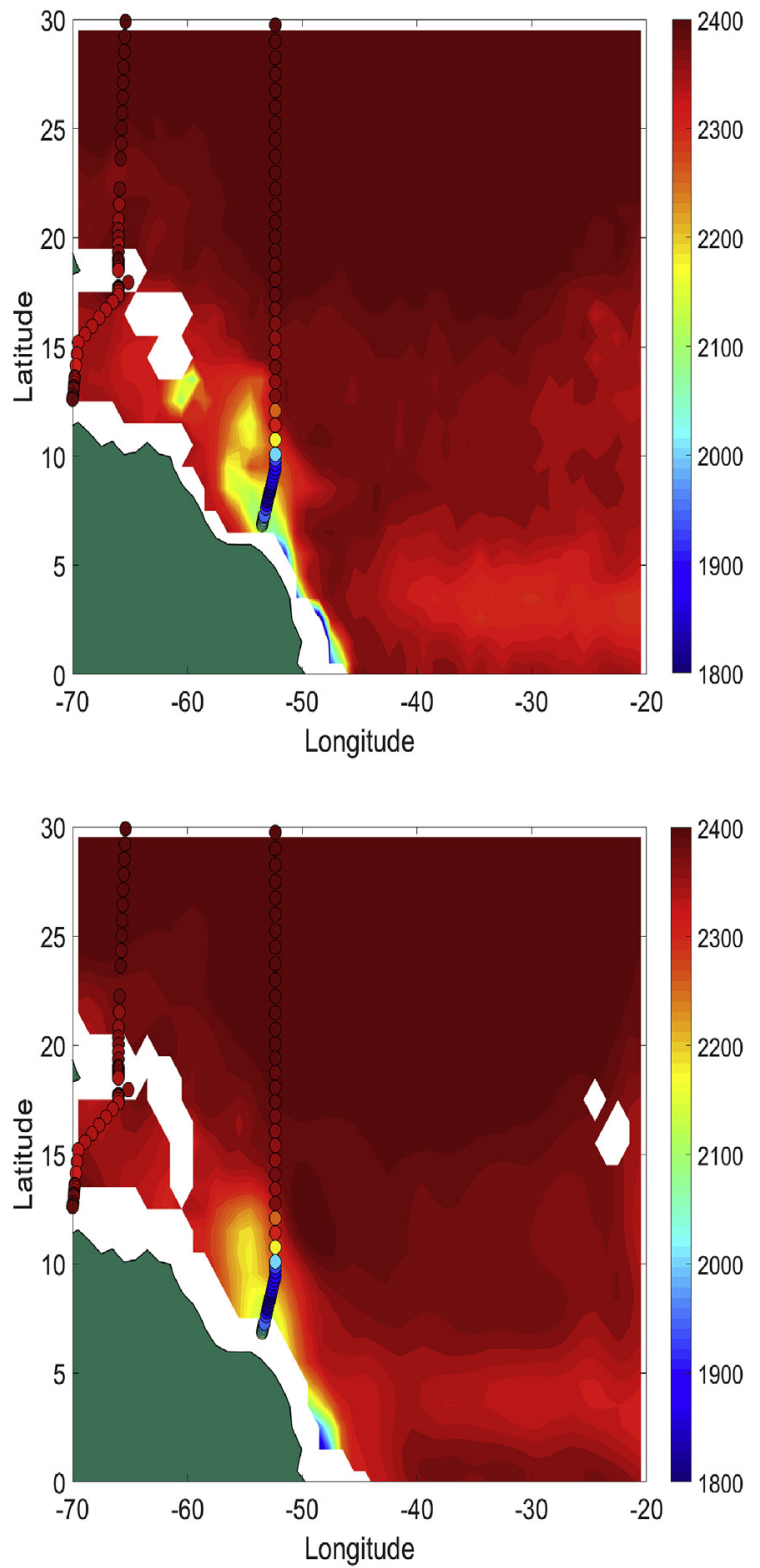

(A)

Fig. 8. Synoptic scale Aquarius (A) and SMOS (B) derived AT in $\mu$ mol kg- 1 for April 2012 using the TS13 algorithm and WOA nitrate, with monthly SMOS and Aquarius SSS. In situ observations collected in April and May 2012 from the GLODAPv2 dataset are overlaid as circles. The May 2012 in situ observations are all within the offshore region (latitude $>20^{\circ} \mathrm{N}$ ).

reduction) for $\mathrm{A}_{\mathrm{T}}$ and from 67 to $50 \mu \mathrm{mol} \mathrm{kg}^{-1}$ (26\%) for $\mathrm{C}_{\mathrm{T}}$.

\subsection{Comparison of $A_{T}$ with $C_{T}$}

Results are shown in Dataset S23, showing that in direct comparisons at each matchup position, the $A_{T}$ outputs have a $42 \%$ lower RMSDe than $C_{\mathrm{T}}$ globally, $41 \%$ lower in the Bay of Bengal and $21 \%$ lower in the Caribbean, indicating that $\mathrm{A}_{\mathrm{T}}$ outputs can generally be retrieved more successfully than $C_{T}$ outputs. However, $A_{T}$ has a $13 \%$ higher RMSDe than $\mathrm{C}_{\mathrm{T}}$ in the Amazon and 9\% higher in the low salinity Amazon using the same algorithms as in the global case, so this relationship is not universal.

\subsection{Multi-year synoptic observations}

The methods evaluated here enable the first multi-year synoptic scale observations of $\mathrm{A}_{\mathrm{T}}$ and $\mathrm{C}_{\mathrm{T}}$ spatial mixing and distributions. To demonstrate their application we characterise the synoptic scale, extent and influence of river-flow-dominated alkalinity mixing in the Amazon plume and western North Atlantic. The Amazon Plume exhibits a twoend-member alkalinity-salinity mixing regime, resulting in a strong linear relationship between alkalinity and salinity (Cai et al., 2010), and mixing between river water and seawater is the dominant controlling factor of the alkalinity-salinity relationship in the western North Atlantic (Jiang et al., 2014). The accuracy assessment means that we can illustrate SMOS or Aquarius observational-based $C_{T}$ and $A_{T}$ monitoring of the Amazon plume along with a calculated estimate of the combined uncertainty in $\mathrm{C}_{\mathrm{T}}$ and $\mathrm{A}_{\mathrm{T}}$ (provided by the RSMDe and bias).

To simplify the interpretation we present results using the same algorithm for monthly SMOS and Aquarius, so that any differences are due solely to the SSS source. For $\mathrm{A}_{\mathrm{T}}$, the best output with both SMOS and Aquarius is TS13 with WOA nitrate, with RMSDe of $57.7 \mu \mathrm{mol} \mathrm{kg} \mathrm{g}^{-1}$ for SMOS and $58.4 \mu \mathrm{mol} \mathrm{kg}{ }^{-1}$ for Aquarius. For Ct the best Aquarius outputs use different algorithms to the best SMOS outputs, and perform less well. Therefore for simplicity we present results of using SMOS and Aquarius with a single algorithm and input pairing (L00 and climatological CORA SST), with RMSDe of $45.0 \mu \mathrm{mol} \mathrm{kg}^{-1}$ for SMOS and $52.2 \mu \mathrm{mol} \mathrm{kg}^{-1}$ for Aquarius. We calculated $\mathrm{A}_{\mathrm{T}}$ and $\mathrm{C}_{\mathrm{T}}$ time series for the Amazon plume using the above algorithm and input pairings, producing monthly Aquarius and SMOS derived $\mathrm{A}_{\mathrm{T}}$ and $\mathrm{C}_{\mathrm{T}}$ collectively covering the time period 2010 to 2016 .

Fig. 6 shows the regional $\left(0-15^{\circ} \mathrm{N}, 45-62^{\circ} \mathrm{W}\right)$ mean SMOS and Aquarius SSS, climatological CORA SST, output $\mathrm{A}_{\mathrm{T}}$ and output $\mathrm{C}_{\mathrm{T}}$, in relation to climatological Amazon discharge data from the Obidos gauge located $750 \mathrm{~km}$ from the ocean (Perry et al., 1996). The discharge data are only provided as an indication of variations in Amazon discharge and will not represent the total flow (Salisbury et al., 2011). In a given month with both SMOS and Aquarius data, we calculate mean SSS using only cells in which both have valid data, in order to compare like with like. If this is not done, and one dataset extends into a low salinity region not covered by the other, large spurious differences can occur, e.g. in May 2014 inconsistent masking causes the regional mean Aquarius SSS to be 1.24 units lower than SMOS SSS (results not shown), a difference that reduced to 0.07 units with consistent masking. Maximum SSS consistently occurs during December and January and minimum SSS occurs during May-July, 1-3 months after the maximum discharge in April, both of which are consistent with previous findings (Salisbury et al., 2011). As expected, $A_{T}$ and $C_{T}$ maxima occur in phase with the variations in SSS, and typically lag the peaks in SST by one to two months, with regional $\mathrm{A}_{\mathrm{T}}$ each year varying between 2230 and $2370 \mu \mathrm{mol} \mathrm{kg}^{-1}$ and $\mathrm{C}_{\mathrm{T}}$ varying between 1890 and $2000 \mu \mathrm{mol} \mathrm{kg}{ }^{-1}$.

Fig. 7 reveals the seasonal patterns in $A_{T}$ over the same period as shown in Fig. $6 \mathrm{~B}$ in relation to the dynamics of the Amazon discharge and their interaction offshore with the along-shore North Brazilian Current, North Equatorial Counter Current and Guyana Current. The August 2011 SSS conditions are shown in Fig. 7A. Clear annual cycles and river plume features are apparent in the observed $A_{T}$, with the Amazon plume influencing $A_{T}$ more than $1000 \mathrm{~km}$ offshore of the mouth of the Amazon (Fig. 7B-D). During June-July each year, very low $\mathrm{A}_{\mathrm{T}}$ values reaching below $2100 \mu \mathrm{mol} \mathrm{kg}^{-1}$ are apparent at the mouth of the Amazon (Fig. 7D), the timing of which is consistent with the observed annual minima in SSS (Salisbury et al., 2011) (see also Fig. 6). Further west the river plume spreads out as it interacts with the along-shore currents, resulting in $\mathrm{A}_{\mathrm{T}}$ in the region of $\sim 2150 \mu \mathrm{mol} \mathrm{kg}^{-1}$ up to $\sim 1700 \mathrm{~km}$ offshore (regions of yellow up to $\sim 17^{\circ} \mathrm{N}$ in Fig. $3 \mathrm{C}$ ). The Amazon plume has been observed to bifurcate during the northern hemisphere summer months (Del Vecchio and Subramaniam, 2004), with one part of the river plume heading north-west and a second jet 


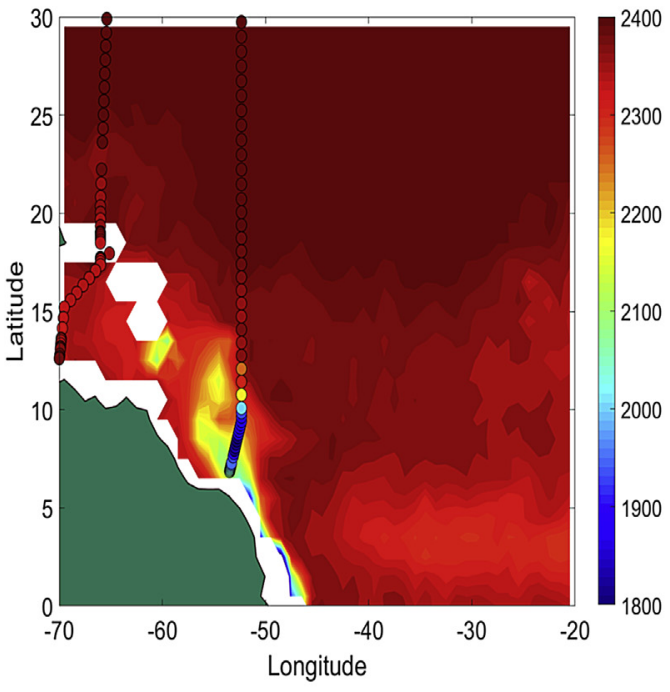

(A)

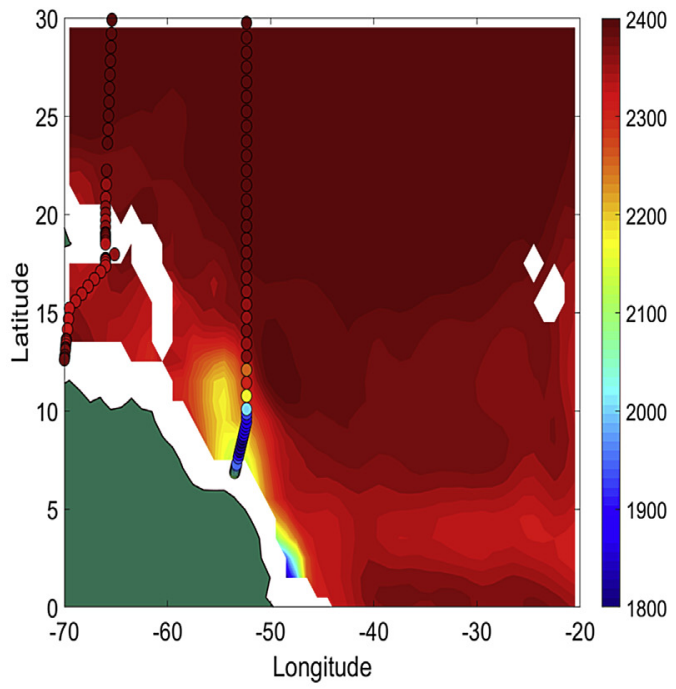

(B)

Fig. 9. Synoptic scale Aquarius (A) and SMOS (B) derived CT in $\mu$ mol kg-1 for April 2012 using the L00 algorithm, CORA SST climatology and WOA nitrate, with monthly SMOS and Aquarius SSS. In situ observations collected in April and May 2012 from the GLODAPv2 dataset are overlaid as circles. The May 2012 in situ observations are all within the offshore region (latitude $>20^{\circ} \mathrm{N}$ ).

\section{Table 6}

Testing the sensitivity of the output uncertainties to the satellite remote sensing input data uncertainties using all global AT algorithms (TS13, Lee06, Lee00, S13 and S13g) with climatological WOA inputs perturbed by exemplar uncertainties from the literature (for SST, Merchant et al., (2014) gives $\pm 0.15{ }^{\circ} \mathrm{C}$; for SSS, Boutin et al., (2018) gives \pm 0.2 ). The output uncertainties are given as a percentage of the unperturbed value and the quoted values are the maximum open-ocean uncertainties calculated for all data within latitudes $< \pm 60^{\circ}$.

\begin{tabular}{lll}
\hline \multirow{2}{*}{ Algorithm } & Uncertainty in AT due to SSS (\%) & Uncertainty in AT due to SST (\%) \\
\hline TS13 & $< \pm 0.8$ & N $/$ A \\
Lee06 & $< \pm 0.7$ & $< \pm 0.2$ \\
Lee00 & $< \pm 0.9$ & $< \pm 0.2$ \\
S13 & $< \pm 0.6$ & $< \pm 0.1$ \\
S13g & $< \pm 0.6$ & $< \pm 0.1$ \\
\hline
\end{tabular}

retroflected to the east (Salisbury et al., 2011). This bifurcation is apparent each year around August (Fig. 7A-D), with an isolated feature of $\mathrm{A}_{\mathrm{T}}$ around $2000-2100 \mu \mathrm{mol} \mathrm{kg}{ }^{-1}$ appearing 500-1000 $\mathrm{km}$ offshore and to the east of the river mouth, although this feature was less pronounced during 2014 (regions of yellow between $5-10^{\circ} \mathrm{N}$ in Fig. 7D).

Fig. 8 shows Aquarius and SMOS monthly $\mathrm{A}_{\mathrm{T}}$ for April 2012 overlaid with 100 in situ $A_{T}$ observations from the GLODAPv2 dataset (Olsen et al., 2016) collected at $3 \mathrm{~m}$ nominal depth during 13 consecutive days in April and May 2012, and Fig. 9 shows the equivalent plot for $\mathrm{C}_{\mathrm{T}}$. Despite the different temporal resolutions, the change in magnitude of the observations (the gradient) between the open ocean data and those close to, and within the river plume, are generally comparable to the synoptic scale observations. The high monthly temporal variations along the $\sim 52^{\circ} \mathrm{W}$ latitudinal transect are illustrated in Fig. 7D. The differences between in situ and synoptic scale observations are discussed in section 3.3. This comparison highlights the power of the synoptic scale observations, allowing the in situ observations to be placed within their wider spatial and temporal context. It also highlights how the synoptic observations characterise the distributions and mixing at the very surface of the water column and how these can be different from that observed in situ (at a nominal depth of $3 \mathrm{~m}$ ), particularly in regions of strong river plume influence. Figs. 8 and 9 could suggest that lower values of $A_{T}$ and $C_{T}$ are found below the surface in the coastal region, whereas offshore the salinity, $\mathrm{A}_{\mathrm{T}}$ and $\mathrm{C}_{\mathrm{T}}$ are vertically well mixed. A combination of in situ and synoptic scale observations could be used to understand the near-surface vertical profile of $A_{T}$.

\section{Discussion}

\subsection{Bay of Bengal}

Because there are permanent and strong radio-frequency interference sources around the coasts of Asia, SSS measurements from SMOS and Aquarius are likely to be of a lower quality in the Bay of Bengal. However, the paucity of in situ measurements in the Bay of Bengal in the satellite salinity era makes comparison difficult. The Bay of Bengal in situ $\mathrm{A}_{\mathrm{T}}$ data measured in 2014 were not included in the main analysis due to their proximity to the coast (and so were removed due to the masking), and their inclusion causes the RMSDe of HG2 to increase to over $600 \mu \mathrm{mol} \mathrm{kg}^{-1}$ (Fig. S1). This demonstrates the importance of comparing like with like when evaluating the outputs and also highlights the influence of focusing on evaluation data without terrigenous influence. The low number of in situ data points used in the Bay of Bengal accuracy assessment highlights that the evaluation of output datasets (from both satellites and re-analysed in situ) will be biased against small-scale variability that may be captured by the in situ observation data used for the evaluation, particularly when in situ validation sites are relatively near-shore and the effect of riverine water flow is more pronounced. This was the case for the 2014 in situ dataset that was omitted from the main accuracy assessment due to falling within the masked area: the site was part of the Sundarbans Biological Observatory Time Series, representing the coastal part of the Sundarbans mangrove ecoregion, which can act as a source and a sink of $\mathrm{CO}_{2}$ during pre-monsoon (April-May) (Akhand et al., 2017), and it is also an area that receives high freshwater discharge $\left(\sim 42000 \mathrm{~m}^{3} \mathrm{~s}^{-1}\right)$ along with local heavy seasonal precipitation, in addition to increasing anthropogenic pressure (Choudhury et al., 2015). The other case study regions have more data available for comparison and therefore this variability may be averaged out in the in situ data binning process. It is essential that more in situ carbonate system data are collected to elucidate these issues for this complex region (the Bay of Bengal), which has a strong riverine influence, and to characterise the variability on a wider scale than has currently been observed (Sarma et al., 2012; Samanta et al., 2015).

A large area of the Bay of Bengal is characterized by $\mathrm{pCO}_{2}$ levels far 
below the atmospheric value (i.e. a large gradient between atmospheric and oceanic $\mathrm{pCO}_{2}$ ), which is more prominent during the north-east monsoon when the air-sea $\mathrm{pCO}_{2}$ gradient exceeds $100 \mu$ atm (Akhand et al., 2013; Ganguly et al., 2011). The enhanced gradient is possibly due to new biological production sustained by excessive nutrient inputs from the Ganga-Brahmaputra-Meghna river basins, thus influencing the carbonate system via net organic production. Additionally, the presence of non-carbonate alkalinity in these regions (e.g. riverine contributions of organic species including humic acid) can result in $A_{T}$ that is not correlated with salinity (Akhand et al., 2013). Only 14 of the outputs overlapped in space and time with the 2014 in situ data that captured this very near-shore variability, resulting in the apparent poor performance of these 14 outputs before coastal masking. If the other outputs had also captured this near-shore variability they may also have had reduced performance. Low satellite SSS coverage due to the issues of radio-frequency interference described above will have also contributed to lower performance of the satellite data driven outputs in this region. Improvements in satellite data coverage in coastal regions together with increased in situ data are likely to begin resolving these issues.

\subsection{The need for continued efforts in quantifying uncertainties}

The problem of uncertainties, and their propagation through the analysis, is an ongoing one. Here, the estimated uncertainties in the in situ measurements used for the evaluation and algorithm uncertainties were included in the analysis where they were quantifiable (i.e. nominal uncertainties for the $\mathrm{C}_{\mathrm{T}}$ and $\mathrm{A}_{\mathrm{T}}$ in situ evaluation measurements and the propagation of the empirical algorithm uncertainties). Published remote sensing uncertainties are available, however no such information exists for the other input datasets; and even within the carbonate system there are still many challenges to fully defining in situ and laboratory measurement uncertainties (Andrew Dickson, pers. comms.; Bockmon and Dickson, 2015). Therefore, quantification of associated uncertainties for all of the input data sources requires continued work. Furthermore, unavoidably in this analysis, data used to evaluate the algorithm outputs were unlikely to be wholly independent from the data used to create the algorithms. In order to have a fully independent evaluation dataset, original datasets would be required to develop the algorithms whilst keeping enough data separate from the algorithm development process to enable an independent evaluation. This was not possible in this initial assessment due to the general dearth of measurements in some regions, and due to ambiguity over which measurements were used to develop the historical algorithms.

However in relation to the calculated combined uncertainties of our outputs, the estimated combined uncertainties from Fine et al. (2017) of smaller than $\pm 20 \mu \mathrm{mol} \mathrm{kg}^{-1}$ for retrieving global $\mathrm{A}_{\mathrm{T}}$ using satellite salinity and SST are consistent with our global results of RMSDe of $17 \mu \mathrm{mol} \mathrm{kg}^{-1}$, bias $<5 \mu \mathrm{mol} \mathrm{kg}{ }^{-1}$. This gives further confidence in the approach taken here. We note however that Fine et al., 2017 misinterpreted the uncertainty information provided by Olsen et al. (2016), as Olsen et al. only state the bias, which as previously discussed is only one component of a Type A uncertainty.

To test the sensitivity of the output uncertainties to the SST and SSS satellite remote sensing input data uncertainties, the latter were propagated through the analysis for all global empirical $A_{T}$ algorithms (TS13, Lee06, Lee00, S13, S13g) for two example months (January and July). This results in $\mathrm{A}_{\mathrm{T}}$ output uncertainties (due solely to satellite SSS and SST input data) of 0.2 to $0.8 \%$ (Table 6), which is close to the nominal in situ uncertainties of $0.5 \%$, or $\pm 10 \mu \mathrm{mol} \mathrm{kg} \mathrm{kg}^{-1}$. The combined uncertainty in most of the studied regions is considerably greater than this, implying that (in the global case at least) the other components of the uncertainty budget dominate over the remote sensing input data uncertainty.

\subsection{The need for algorithm retraining and the collection of in situ observations}

Only seven global and five regional algorithms were presented here, in addition to output of $\mathrm{A}_{\mathrm{T}}$ and $\mathrm{C}_{\mathrm{T}}$ from HG2, primarily because these were the only algorithms from the published literature that did not require additional re-parameterization for all the case study regions. Future efforts are needed to perform this re-fitting, not only for additional $\mathrm{A}_{\mathrm{T}}$ and $\mathrm{C}_{\mathrm{T}}$ algorithms, but also for the remaining carbonate system parameters $\left(\mathrm{pCO}_{2}\right.$ and $\left.\mathrm{pH}\right)$. This is a demanding task; with just the 14 algorithms and model outputs used here, 1070 outputs were compared in the round-robin comparisons. Further, where few in situ measurements of a carbonate variable exist (e.g. pH), information could be obtained for future assessments by calculating this variable from two of the other carbonate variables (e.g. $\mathrm{C}_{\mathrm{T}}$ and $\mathrm{A}_{\mathrm{T}}$ ) along with temperature and salinity. Calculating the variable in this way does introduce additional uncertainties, thus to be truly beneficial, such outputs should include the propagation of all uncertainties. A future assessment of the exploitation of satellite SSS will require further analysis of temporally resolved (rather than climatological) satellite observations, using new in situ data. We found only three cruises within GLODAPv2 that overlap with satellite salinity observations in our regions: none in the Bay of Bengal, one in the Amazon plume at the beginning of May 2010 (the first month of reliable SMOS data after its launch in November 2009) and two in the Amazon plume in April and May 2012 (shown in Figs. 8 and 9), one of which overlapped with the Greater Caribbean (only 6\% and $3 \%$ of the GLODAPv2 data correspond to SMOS and Aquarius eras respectively). Hence coverage where we have both in situ and satellite observations is very limited spatially, seasonally and interannually, highlighting the need for further in situ data. It should also be noted that the lowest uncertainties achieved using these satellite observationbased and empirical approaches are still greater than the nominal in situ and laboratory measurement uncertainties (of $\pm 10 \mu \mathrm{mol} \mathrm{kg}^{-1}$ ) so the methods presented here are unlikely to ever be a substitute for in situ measurements. Their strength is in providing synoptic data to fill the inevitable gaps in the in situ data coverage. To enable all new in situ data to be fully exploited by the Earth observation community they need to have been collected following international protocols (as defined by Dickson et al., 2007), analysed using traceable standards (as advocated by Bockmon and Dickson, 2015) enabling the provision of a complete uncertainty budget (quantified as a Type A uncertainty, BIPM, 2008). If possible, the historical data contained within the GLODAPv2 dataset would benefit from the inclusion of some indication of their uncertainty budget e.g. a simple 'high', 'low' or 'unknown' determined using existing metadata and/or expert interpretation and opinion via a Type B uncertainty approach as defined by BIPM (2008). Similarly, the CORA re-analysis and WOA climatology data would benefit from similar additions as these datasets lack any uncertainty information.

\subsection{Earth system model performance}

It should be noted that we would not expect a free running global Earth system model such as HG2 to perform well regionally, though the poor global $\mathrm{A}_{\mathrm{T}}$ performance and the relatively good performance in the Amazon plume were surprising. We include HG2 in the comparison mainly to illustrate how this methodology could be used to compare model data with quite different input sources such as satellite data. Our results provide a potentially useful dataset (including uncertainty information) to evaluate and challenge Earth system model outputs.

\section{Conclusions}

We demonstrate that satellite SSS and SST data are, in conjunction with empirical algorithms, able to successfully reproduce both $\mathrm{A}_{\mathrm{T}}$ and $\mathrm{C}_{\mathrm{T}}$ in four regions (globally, the Caribbean, the Amazon and the low salinity Amazon) as well as or better than in situ-derived (re-analysed) 
SSS and SST using the same empirical algorithms, or a global Earth system model dataset, with the advantage that satellite datasets are acquired daily, on average, with synoptic coverage.

The ability to derive key surface carbonate system parameters from satellite observed SSS and SST offers the potential for quantifying natural variability, as well as monitoring the present state of these important parameters through space and time. Satellite sensors provide a significant advantage over traditional in situ derived climatologies because of the ability to provide synoptic and frequent observations of global oceans. Critically, many of the satellites that provide these data are already in operation, hence historic satellite sensor datasets could be used with these algorithms to elucidate changes over longer periods of time. These satellite methods should not replace ongoing in situ measurements, but should complement and enhance them by providing observations in periods where there are gaps in both time and space. Ongoing in situ data are essential to improve our ability to exploit satellite data, for example through enhanced parameterization of the algorithms. Satellites are also only able to measure surface waters, and are unable to measure under ice. These gaps must be filled with in situ data. Similarly, the evolving nature of the carbonate system due to anthropogenic forcing means that it is likely that these empirical algorithms will need to be periodically re-trained to maintain their performance. Hence the algorithms and methods utilized are useful for studying seasonal and inter-annual variations and episodic events, but may not be suitable for resolving longer-term trends.

The assessment presented here, which represents a significant effort and extensive analysis, provides the baseline performance against which any future algorithm re-training or re-calibration attempts can be compared.

\section{Acknowledgments}

This work was funded by the European Space Agency (ESA) Support to Science Element (STSE) Pathfinders Ocean Acidification project (contract No. 4000110778/14/I-BG, http://www.pathfindersoceanacidification.org/) with additional support from the ESA Satellite Oceanographic Datasets for Acidification, OceanSODA, (contract No. 4000112091/14/I-LG, https://www.esa-oceansoda.org/). The authors thank Professor Andrew Dickson, Scripps Institution of Oceanography, for discussions about carbonate chemistry uncertainties and error propagation.

\section{Appendix A. Supplementary data}

Supplementary data to this article can be found online at https:// doi.org/10.1016/j.rse.2019.111469.

\section{References}

Akhand, A., Chanda, A., Dutta, S., 2013. Characterizing air-sea $\mathrm{CO}_{2}$ exchange dynamics during winter in the coastal water off the Hugli-Matla estuarine system in the northern Bay of Bengal, India. J. Oceanogr. 69, 687-697.

Akhand, A., et al., 2017. Potential $\mathrm{CO}_{2}$ emission due to loss of above ground biomass from the Indian sundarban mangroves during the last four decades. J. Indian Soc. Remote Sens. 45 (1), 147-154.

Bates, N.R., et al., 2012. Detecting anthropogenic carbon dioxide uptake and ocean acidification in the North Atlantic Ocean. Biogeosciences 9, 2509-2522. https://doi. org/10.5194/bg-9-2509-2012.

BIPM, 2008. Evaluation of measurement data - guide to the expression of uncertainty in measurement. JCGM 100, 2008.

Bockmon, E.E., Dickson, A.G., 2015. An inter-laboratory comparison assessing the quality of seawater carbon dioxide measurements. Mar. Chem. 171, 36-43. https://doi.org/ 10.1016/j.marchem.2015.02.002.

Bonou, F.K., Noriega, C., Lefèvre, N., Araujo, M., 2016. Distribution of $\mathrm{CO}_{2}$ parameters in the western tropical Atlantic Ocean. Dyn. Atmos. Oceans 73, 47-60. https://doi.org/ 10.1016/j.dynatmoce.2015.12.001.

Boutin, J., Martin, N., Reverdin, G., Yin, X., Gaillard, F., 2013. Sea surface freshening inferred from SMOS and ARGO salinity: impact of rain. Ocean Sci. 9, 183.

Boutin, J., et al., 2016. Satellite and in situ salinity: understanding near-surface stratification and subfootprint variability. Bull. Am. Meteorol. Soc. 97, 1391-1407.

Boutin, J., Vergrly, J.L., Marchand, S., D'Amico, F., Hasson, A., Kolodziejczyk, N., Reul,
N., Reverdin, G., Vialard, J., 2018. New SMOS Sea Surface Salinity with reduced systematic errors and improved variability. Remote Sens. Environ. 214, 115-134. https://doi.org/10.1016/j.rse.2018.05.022.

Brix, H., Gruber, N., Keeling, C.D., 2004. Interannual variability of the upper ocean carbon cycle at station ALOHA near Hawaii. Glob. Biogeochem. Cycles 18. https:// doi.org/10.1029/2004GB002245.

Bushinsky M., S., et al., 2019. Observing Changes in Ocean Carbonate Chemistry: Our Autonomous Future. Current Climate Change Reports 5 (3), 207-220.

Byrne, R.H., 2014. Measuring Ocean Acidification: new technology for a new era of ocean chemistry. Environ. Sci. Technol. 48 (10), 5352-5360.

Cabanes, C., et al., 2013. The CORA dataset: validation and diagnostics of in-situ ocean temperature and salinity measurements. Ocean Sci. 9, 1-18. https://doi.org/10. 5194/os-9-1-2013.

Cai, W.-J., et al., 2010. Alkalinity distribution in the western North atlantic ocean margins. J. Geophys. Res.: Oceans 115, n/a. https://doi.org/10.1029/2009JC005482.

Caldeira, K., Wickett, M.E., 2005. Ocean model predictions of chemistry changes from carbon dioxide emissions to the atmosphere and ocean. J. Geophys. Res. Ocean. https://doi.org/10.1029/2004JC002671.

Chao, Y., Farrara, J.D., Schumann, G., Andreadis, K.M., Moller, D., 2015. Sea surface salinity variability in response to the Congo River discharge. Cont. Shelf Res. 99, $35-45$.

Choudhury, A.K., Das, M., Philip, P., Bhadury, P., 2015. An assessment of the implications of seasonal precipitation and anthropogenic influences on a mangrove ecosystem using phytoplankton as proxies. Estuar. Coasts 38, 854-872.

Cooley, S.R., Coles, V.J., Subramaniam, A., Yager, P.L., 2007. Seasonal variations in the Amazon plume-related atmospheric carbon sink. Glob. Biogeochem. Cycles 21, n/a. https://doi.org/10.1029/2006GB002831.

Del Vecchio, R., Subramaniam, A., 2004. Influence of the Amazon river on the surface optical properties of the western tropical North Atlantic ocean. J. Geophys. Res.: Oceans 109.

Dickson, A. G., Sabine, C. L., Christian, J. R. Guide to Best Practices for Ocean $\mathrm{CO}_{2}$ Measurements, PICES Special Publication. (North Pacific Marine Science Organization, 2007).

Dickson G., A., Riley P., J., 1978. The effect of analytical error on the evaluation of the components of the aquatic carbon-dioxide system. Marine Chemistry 6 (1), 77-85. https://doi.org/10.1016/0304-4203(78)90008-7.

Drucker, R., Riser, S.C., 2014. Validation of Aquarius sea surface salinitdy with Argo: analysis of error due to depth of measurement and vertical salinity stratification. J. Geophys. Res. Oceans 119, 4626-4637.

Findlay F., H., et al., 2008. Carbon and nutrient mixed layer dynamics in the Norwegian sea. Biogeosciences 5 (5), 1395-1410. https://doi.org/10.5194/bg-5-1395-2008.

Fine, R.A., Willey, D.A., Millero, F.J., 2017. Global variability and changes in ocean total alkalinity from Aquarius satellite data. Geophys. Res. Lett. 44, 261-267. https://doi. org/10.1002/2016GL071712.

Friis, K., Körtzinger, A., Wallace, D.W.R., 2003. The salinity normalization of marine inorganic carbon chemistry data. Geophys. Res. Lett. 30. https://doi.org/10.1029/ 2002GL015898.

Ganguly, D., et al., 2011. Coupled micrometeorological and biological processes on atmospheric $\mathrm{CO}_{2}$ concentrations at the land-ocean boundary, NE coast of India. Atmos. Environ. 45, 3903-3910.

Garcia E., H., et al., 2014a. World ocean atlas 2013. Volume 3, Dissolved oxygen, apparent oxygen utilization, and oxygen saturation, edited by: Levitus, S. A. Mishonov Technical Ed., NOAA Atlas NESDIS 75.

Garcia, H.E., et al., 2014b. World ocean atlas 2013. Volume 4, Dissolved inorganic nutrients (phosphate, nitrate, silicate), edited by: Levitus, S. A. Mishonov Technical Ed., NOAA Atlas NESDIS 76.

Gledhill, D.K., Wanninkhof, R., Millero, F.J., Eakin, M., 2008. Ocean acidification of the greater Caribbean region 1996-2006. J. Geophys. Res. 113, C10031. https://doi.org/ 10.1029/2007jc004629.

Gledhill, D.K., Wanninkhof, R., Eakin, C.M., 2009. Observing ocean acidification from space. Oceanography 22.

Ibánhez, J.S.P., Araujo, M., Lefèvre, N., 2016. The overlooked tropical oceanic $\mathrm{CO}_{2}$ sink. Geophys. Res. Lett. 43, 3804-3812.

International Hydrographic Organization, 1953. 3 edn. Limits of Oceans and Seas, Special Publication 23 International Hydrographic Organization.

Jiang, Z.P., Tyrrell, T., Hydes, D.J., Dai, M., Hartman, S.E., 2014. Variability of alkalinity and the alkalinity-salinity relationship in the tropical and subtropical surface ocean. Glob. Biogeochem. Cycles 28, 729-742.

Johnson, K.S., Plant, J.N., Coletti, L.J., Jannasch, H.W., Sakamoto, C.M., Riser, S.C., Swift, D.D., Williams, N.L., Boss, E., Haëntjens, N., Talley, L.D., Sarmiento, J.L., 2017. J. Biogeochemical sensor performance in the SOCCOM profiling float array. Geophys. Res. Ocean. 122, 6416-6436. https://doi.org/10.1002/2017JC012838.

Jones, C.D., et al., 2011. The HadGEM2-ES implementation of CMIP5 centennial simulations. Geosci. Model Dev. (GMD) 4, 543-570. https://doi.org/10.5194/gmd-4-5432011.

Kroeker, K.J., et al., 2013. Impacts of ocean acidification on marine organisms: quantifying sensitivities and interaction with warming. Glob. Chang. Biol. 19, 1884-1896. https://doi.org/10.1111/gcb.12179.

Lagerloef, G., Kao, H.Y., Meissner, T., Vazquez, J., 2015. Aquarius Salinity Validation Analysis; Data Version 4.0. Earth Space Res., Seattle, WA, USA.

Land, P.E., et al., 2015. Salinity from space unlocks satellite-based assessment of ocean acidification. Environ. Sci. Technol. 49, 1987-1994 doi:10.102/es504849.

Land, P.E., Findlay, H.S., Shutler, J.D., Ashton, I.G.C., Grouazel, A., Girard-Ardhuin, F., Reul, N., Piolle, J.-F., Chapron, B., Quilfen, Y., Bellerby, R.G.J., Bhadury, P., Salisbury, J., Vandemark, D., Sabia, R., 2019. Results and analysis of oceanic total alkalinity and dissolved inorganic carbon estimated from space borne, interpolated in 
situ, climatological and Earth system model data. PANGAEA. https://doi.org/10. 1594/PANGAEA.898115.

Le Vine, D.M., et al., 2014. Aquarius: status and recent results. Radio Sci. 49, 709-720. https://doi.org/10.1002/2014RS005505.

Lee, K., Wanninkhof, R., Feely, R.A., Millero, F.J., Peng, T.H., 2000. Global relationships of total inorganic carbon with temperature and nitrate in surface seawater. Glob. Biogeochem. Cycles 14, 979-994.

Lee, K., et al., 2006. Global relationships of total alkalinity with salinity and temperature in surface waters of the world's oceans. Geophys. Res. Lett. 33.

Lefèvre, N., Diverrès, D., Gallois, F., 2010. Origin of $\mathrm{CO}_{2}$ undersaturation in the western tropical Atlantic. Tellus B 62, 595-607. https://doi.org/10.1111/j.1600-0889.2010. 00475.x.

Lentz, S.J., Limeburner, R., 1995. The Amazon river plume during AMASSEDS: spatial characteristics and salinity variability. J. Geophys. Res.: Oceans 100, 2355-2375.

Locarnini A., R., et al., 2013. World Ocean Atlas 2013, Volume 1: Temperature, edited by: Levitus, S. A. Mishonov Technical Ed., NOAA Atlas NESDIS 73.

Merchant, C.J., et al., 2012. A 20 year independent record of sea surface temperature for climate from Along-Track Scanning Radiometers. J. Geophys. Res.: Oceans 117 1978-2012.

Merchant, C.J., et al., 2014. sea Surface temperature datasets for climate applications from phase 1 of the european space agency climate change initiative (SST CCI). Geosci. Data J. 1, 179-191.

Millero, F.J., Lee, K., Roche, M., 1998. Distribution of alkalinity in the surface waters of the major oceans. Mar. Chem. 60, 111-130.

Olsen, A., et al., 2016. The Global Ocean Data Analysis Project version 2 (GLODAPv2) an internally consistent data product for the world ocean. Earth Syst. Sci. Data 8, 297-323. https://doi.org/10.5194/essd-8-297-2016.

Osterman, G.B., Eldering, A., Avis, C., Chafin, B., O'Dell, C.W., Frankenberg, C., Fisher, B.M., Mandrake, L., Wunch, D., Granat, R., 2016. Orbiting Carbon Observatory-2 (OCO-2) Data Product User's Guide, Operational L1 and L2 Data Versions 7 and 7R. Jet Propulsion Laboratory, Pasadena, CA, USA.

Perry, G.D., Duffy, P.B., Miller, N.L., 1996. An extended data set of river discharges for validation of general circulation models. J. Geophys. Res.: Atmosphere 101, 21339-21349.

Raven, J.A., Caldeira, K., Elderfield, H., Hoegh-Guldberg, O., Liss, P.S., Riebesell, U., et al., 2005. Ocean Acidification Due to Increasing Atmospheric Carbon Dioxide 12/ 05 The Royal Society, Policy document.

Reul, N., et al., 2012. Overview of the first SMOS sea surface salinity products. Part I: quality assessment for the second half of 2010. IEEE Trans. Geosci. Remote Sens. 50, 1636-1647.

Reul, N., et al., 2014. Sea surface salinity observations from space with the SMOS satellite: a new means to monitor the marine branch of the water cycle. Surv. Geophys. 35,
681.

Reul, N., Team, I.C.-C., 2015. SMOS Level 3 and 4 Research products of the Centre d'Expertise Ifremer du CATDS -Algorithm Theoretical Background Document. IFREMER-CNES technical document < https://www.catds.fr/ > (2015).

Salisbury, J., et al., 2011. Spatial and temporal coherence between Amazon River discharge, salinity, and light absorption by colored organic carbon in western tropical Atlantic surface waters. J. Geophys. Res.: Oceans 116.

Salisbury, J., et al., 2015. How can present and future satellite missions support scientific studies that address Ocean Acidification? Oceanography 28, 108-121. https://doi. org/10.5670/oceanog.2015.35.

Samanta, S., Dalai, T.K., Pattanaik, J.K., Rai, S.K., Mazumdar, A., 2015. Dissolved inorganic carbon (DIC) and its $\delta 13 \mathrm{C}$ in the Ganga (Hooghly) River estuary, India: evidence of DIC generation via organic carbon degradation and carbonate dissolution. Geochem. Cosmochim. Acta 165, 226-248.

Santana-Casiano, J.M., González-Dávila, M., Rueda, M.J., Llinás, O., González-Dávila, E.F., 2007. The interannual variability of oceanic $\mathrm{CO}_{2}$ parameters in the northeast Atlantic subtropical gyre at the ESTOC site. Glob. Biogeochem. Cycles 21. https://doi. org/10.1029/2006GB002788.

Sarma, V.V.S.S., et al., 2012. Sources and sinks of $\mathrm{CO}_{2}$ in the west coast of Bay of Bengal. Tellus B 64, 10961. https://doi.org/10.3402/tellusb.v64i0.10961.

Sasse, T.P., McNeil, B.I., Abramowitz, G., 2013. A novel method for diagnosing seasonal to inter-annual surface ocean carbon dynamics from bottle data using neural networks. Biogeosciences 10, 4319.

Smith, S.V., Key, G.S., 1975. Carbon dioxide and metabolism in marine environments. Limnol. Oceanogr. 20, 493-495.

Takahashi, T., Sutherland, S., 2013. Climatological mean distribution of pH and carbonate ion concentration in Global Ocean surface waters in the Unified $\mathrm{pH}$ scale and mean rate of their changes in selected areas. Report No. OCE 10-38891. National Science Foundation, Washington, D. C., USA.

Takahashi, T., et al., 2009. Climatological mean and decadal change in surface ocean $\mathrm{pCO}_{2}$, and net sea-air $\mathrm{CO}_{2}$ flux over the global oceans. Deep-Sea Res. Pt II 56, 554-577. https://doi.org/10.1016/j.dsr2.2008.12.009.

Taylor, 1997. An Introduction to Error Analysis the Study of Uncertainties in Physical Measurements, second ed. University Science Books.

Ternon, J.F., Oudot, C., Dessier, A., Diverres, D., 2000. A seasonal tropical sink for atmospheric $\mathrm{CO}_{2}$ in the Atlantic ocean: the role of the Amazon River discharge. Mar. Chem. 68, 183-201. https://doi.org/10.1016/S0304-4203(99)00077-8.

Yang, D., Liu, Y., Cai, Z., Chen, X., Yao, L., Lu, D., 2018. First global carbon dioxide maps produced from TanSat measurements. Adv. Atmos. Sci. https://doi.org/10.1007/ s00376-018-7312-6.

Zweng M., M., et al., 2013. World ocean atlas 2013. Volume 2, Salinity. A. Mishonov Technical Ed., NOAA Atlas NESDIS 74. 